This document is published in:

Journal of Monetary Economics (2005), 52 (3), 633-667. DOI: http://dx.doi.org/10.1016/j.jmoneco.2004.06.004

(C) 2005 Elsevier B.V. 


\title{
Minimum consumption and transitional dynamics in wealth distribution
}

\author{
María J. Álvarez-Peláez ${ }^{\mathrm{a}, \mathrm{b}}$, Antonia Díaz ${ }^{\mathrm{c}, *}$ \\ ${ }^{a}$ Institute of Economics, University of Copenhagen, DK-1455 Copenhagen K, Denmark \\ ${ }^{\mathrm{b}}$ Fundación Centro de Estudios Andaluces, CentrA, 41001 Sevilla, Spain \\ ${ }^{\mathrm{c}}$ Department of Economics, Universidad Carlos III, Calle Madrid, 12628093 Getafe, Madrid, Spain
}

\begin{abstract}
This paper investigates quantitatively how initial wealth holding differences across households are propagated through time in a one sector growth model economy. A key feature of the model is that household consumption cannot fall below a positive level each period. The existence of a minimum consumption requirement implies that the Intertemporal Elasticity of Substitution not only differs across households but also changes differently over time. This model is calibrated to match some key aggregate statistics of the U.S. economy. We find that, as in the data, the wealth distribution in our benchmark model economy exhibits a (brief) period of increasing inequality, a short period in which inequality diminishes and a steady level of inequality along the balanced growth path. However, our model illustrates that the evolution of inequality is very sensitive to the length of the transition path. Additionally, our model predicts an upsurge in wealth inequality following the productivity slowdown in the 1970s.
\end{abstract}

JEL classification: D90; E21

Keywords: Minimum consumption; Intertemporal elasticity of substitution; Transitional dynamics; Wealth distribution

* Díaz thanks the Spanish Ministry of Education, DGI, project BEC2001-1653, for financial support. We are grateful to the editor and an anonymous referee for all their comments and suggestions.

Corresponding author. Tel.: + 3491624 5733; fax: + 34916249875 .

E-mail address: andiaz@eco.uc3m.es (A. Díaz). 


\section{Introduction}

There is an extensive literature that investigates the relationship between inequality and growth. The interest in this issue started with Kuznets (1955) who stated his famous conjecture on the non-monotonic relationship between income inequality and level of per capita income. Since then, a host of researchers have explored various channels through which growth affects inequality and vice versa. ${ }^{1}$ In this paper we contribute to the literature that examines the effects of growth on inequality. We study quantitatively the importance of differences in saving rates across households in driving changes in wealth inequality.

To analyze this channel we build a one sector growth model economy in which there is no uncertainty and capital markets are perfect. Households do not differ in labor earnings. The key feature we add to this otherwise standard neoclassical model is that household consumption cannot fall below a positive level in any period, i.e., we assume a minimum consumption requirement. The existence of this requirement implies that the intertemporal elasticity of substitution (IES) not only differs across households with different levels of wealth but also changes differently over time. This different behavior of the IES governs the evolution of saving rates and drives all changes in wealth inequality in our model economy. The existence of perfect capital markets and the quasi-homotheticity of preferences imply that the Engel curves are affine functions of the level of wealth. This property of the model ensures that the distribution of wealth does not affect the aggregate dynamics of the model-provided that no household's income falls below the consumption requirement-, whereas the wealth distribution does change along the transition path.

To assess the quantitative significance of this channel we focus our study on observed patterns of wealth inequality in the U.S. during the period 1870-1970. The model is calibrated to match some key aggregate statistics of the U.S. economy. Wealth distribution in the initial period is set to match historical data from the U.S. for that period. We simulate our model economy and compare the evolution of the wealth distribution of our model with that experienced in the U.S. We find that, as in the data, the wealth distribution in our benchmark model economy exhibits a (brief) period of increasing inequality, a short period in which inequality diminishes and a steady level of inequality once the economy reaches its balanced growth path. The intuition of these results is as follows: for low levels of aggregate income (therefore, of earnings) the existence of a minimum consumption level implies that poor households not only have smaller saving rates but also increase their savings more slowly than wealthy households decrease theirs. This implies a rise in wealth inequality. As aggregate income rises the behavior of the saving rates is reversed. Poor households increase their savings at a faster rate and inequality diminishes. Once the economy reaches its balanced growth path there are no changes in inequality.

\footnotetext{
${ }^{1}$ see Benabou (1996) or Aghion et al. (1999) for a survey of the literature.
} 
Our experiments suggest that the evolution of wealth inequality is very sensitive to the length of the transition path. The reason for this is that the channel of differences in saving rates across households only operate along the transition path, not the balanced growth path. The farther from its steady state an economy is when it starts a process of sustained growth, the longer the period of increasing inequality and the higher its level. The length of the transition path depends on the contribution of total factor productivity growth (TPF, hereafter) and the initial level of aggregate capital. The higher the level of productivity growth, the shorter the period of increasing inequality, if there is any. The reason for this is that the larger the level of TFP growth the sooner the economy attains a level of income above which poor households start accumulating capital faster than wealthy households. Thus, our experiments suggest that differences in Total Factor Productivity growth may help us to understand the different wealth inequality experiences observed across countries. Finally, our model is able to predict an upsurge in wealth inequality following the productivity slowdown that started in the 1970 s.

Other authors have explored the link between differences in saving rates and the dynamics of the wealth distribution. Stiglitz (1969) was among the first to discuss the distributional implications of non-linear consumption functions. Chatterjee (1994) investigates the wealth distribution implications of quasi-homothetic preferences. The main difference between his approach and ours is the measure of wealth used. He investigates the evolution of the distribution of life-time wealth, i.e., the present value of life-time earnings plus the present value of accumulated capital, whereas we define wealth as household net worth. Chatterjee shows analytically that when a minimum consumption requirement exists, the distribution of life-time wealth becomes more unequal along the transition path. We show that the distribution of household net worth can either become more egalitarian or unequal along the transition path, depending on the region of the parameters space considered. Caselli and Ventura (2000) study theoretically the evolution of wealth distribution in a framework similar to ours. They build a model in which households derive utility from a privately produced good and a public good. There are perfect capital markets. The public good in the utility function plays a role similar to a negative minimum consumption requirement. They find a qualitative result similar to ours but do not attempt to quantify its importance. Chatterjee and Ravikumar (1999) also study the link between capital accumulation and inequality along the transition path and introduce a minimum consumption requirement. They generate a Kuznets curve for wealth inequality. As opposed to us, they use a linear technology and calibrate their model to match some key statistics for the Indian economy. Finally, ObiolsHoms and Urrutia (2003) study the evolution of the distribution of wealth in a setup very close to ours. They also consider preferences where there is a minimum consumption but they restrict their analysis to the log-utility function, whereas we extend our analysis to the class of quasi-homothetic preferences used by Chatterjee (1994). Moreover, their study is analytical, whereas our focus is quantitative. 
The key departure of our model from the standard neoclassical framework is that we introduce a minimum consumption requirement which implies that the household's IES increases with household's wealth. Using panel data on Indian villagers, Atkeson and Ogaki $(1996,1997)$ find economically significant differences in the IES across rich and poor households. Rosenzweig and Wolpin (1993) also use Indian data and find a minimum consumption requirement to be statistically significant and to amount to a sizable fraction of consumption expenditures of the average household. Moreover, Rebelo (1992) and Ogaki et al. (1996) argue that low saving rates and low elasticity of savings with respect to the interest rate point to the existence of a minimum consumption requirement. Thus, we think that a minimum consumption requirement is important in understanding the process of capital accumulation and growth.

The rest of the paper is organized as follows: Section 2 describes the economic environment and discusses some theoretical properties of the class of economies considered. Section 3 describes the evidence we have about the evolution of wealth inequality in the U.S. economy for the period 1870-1970. Section 4 describes our calibration procedure. In Section 5 we present our main results. In Section 6 we study the sensitivity of the evolution of the wealth distribution with respect to the level of productivity growth. Section 7 concludes.

\section{The model economy}

We consider a infinite horizon production economy populated by a continuum of households of measure one that live forever. Sections 2.1 and 2.2 describe the technology, preferences and endowments, respectively. Section 2.3 presents the household problem and Section 2.4 provides a formal definition of equilibrium. In Section 2.5 we describe the class of economies to which we restrict our analysis. Section 2.6 shows the properties of the model that will allow us to analyze separately the aggregate behavior of the model and the dynamics of the wealth distribution and analyzes the determinants of the latter.

\subsection{Technology}

Aggregate output, $Y_{t}$, is produced according to an aggregate neoclassical production function that takes as inputs aggregate capital, $K_{t}$, and aggregate labor, $L_{t}, Y=z_{t} F\left(K_{t}, L_{t}\right)$. The final good can be either consumed or invested in capital. Therefore, in every period,

$$
C_{t}+I_{t}=z_{t} F\left(K_{t}, L_{t}\right),
$$

where $C_{t}$ is aggregate consumption and $I_{t}$ is investment. The aggregate stock of capital evolves according to the law $K_{t+1}=(1-\delta) K_{t}+I_{t}$, where $\delta \in$ $(0,1)$ is the depreciation rate of capital. The productivity factor $z_{t}$ grows at a constant rate $\gamma$. 


\subsection{Preferences and endowments}

In each period, households derive utility from consuming a commodity $c$ and have an endowment of one unit of time each period. The size of the household grows at rate $n$. All households have identical preferences defined over consumption at every date,

$$
U=\sum_{t=0}^{\infty} \beta^{t}(1+n)^{t} u\left(c_{t}-\alpha_{t}\right), \quad \beta \in(0,1) .
$$

where $\alpha_{t}$ denotes the subsistence level of per capita consumption at period $t$. We will allow for the amount of consumption considered a "primary necessity" to vary over time. Changes in this minimum level are viewed as exogenous by all households.

\subsection{The household's problem}

The problem solved by household $i$, in per capita terms, is

$$
\begin{array}{cl}
\text { maximize } & \sum_{t=0}^{\infty} \beta^{t}(1+n)^{t} u\left(c_{t}^{i}-\alpha_{t}\right) \\
\text { subject to } & c_{t}^{i}+(1+n) a_{t+1}^{i} \leqslant w_{t}+\left(1+r_{t}\right) a_{t}^{i} \quad \text { for all } t=0, \ldots \\
& a_{t+1}^{i} \geqslant-\underline{a}, \\
& a_{0}^{i} \text { given. }
\end{array}
$$

where $a_{t}^{i}$ denotes household $i$ 's asset holdings at period $t, w_{t}$ stands for the wage and $r_{t}$ is the interest rate net of depreciation. It is implicit in the setting of the household's problem that we are assuming the existence of perfect capital markets: i.e., individuals are able to borrow and lend without any restriction at the market interest rate. We merely require that households cannot borrow an arbitrarily large amount in order to preclude Ponzi schemes.

\subsection{Equilibrium}

Definition 1. An equilibrium for this economy is a sequence of prices $\left\{w_{t}, r_{t}\right\}_{t=0}^{\infty}$, an allocation for each household $i,\left\{c_{t}^{i}, a_{t+1}^{i}\right\}_{t=0}^{\infty}$ and an allocation for the representative firm $\left\{K_{t}, L_{t}\right\}_{t=0}^{\infty}$ such that:

1. The allocation $\left\{c_{t}^{i}, a_{t+1}^{i}\right\}_{t=0}^{\infty}$ solves the household $i$ 's problem shown in (3) given the sequence of prices $\left\{w_{t}, r_{t}\right\}_{t=0}^{\infty}$.

2. Factor prices satisfy $r_{t}=z_{t} F_{K}\left(K_{t}, L_{t}\right)-\delta$, and $w_{t}=z_{t} F_{L}\left(K_{t}, L_{t}\right)$.

3. Markets clear:

(a) $L_{t}=(1+n)^{t}$,

(b) $K_{t}=(1+n)^{t} \int_{0}^{1} a_{t}^{i}$,

(c) $(1+n)^{t} \int_{0}^{1} c_{t}^{i}+K_{t+1}-(1-\delta) K_{t}=z_{t} F\left(K_{t}, L_{t}\right)$. 


\subsection{The class of economies considered}

We restrict our analysis to Cobb-Douglas production functions. Therefore, $Y_{t}=$ $z_{t} K_{t}^{\theta} L_{t}^{1-\theta}$. Moreover, we focus on the class of utility functions

$$
u\left(c_{t}\right)=\frac{\left(c_{t}-\alpha_{t}\right)^{1-\sigma}}{1-\sigma}, \sigma>0 .
$$

Under this class of preferences the household's IES is given by the expression

$$
\mathrm{IES}_{t}^{i}=\frac{c_{t}^{i}-\alpha_{t}}{\sigma c_{t}^{i}} .
$$

Since consumption is an increasing function of wealth, under these preferences, wealthier households have a larger intertemporal elasticity of consumption than poorer households. This implies that both the level and the dynamics of the household' saving rate depends on their level of wealth. We will discuss this point in detail when we present our results in Section 5.

For a balanced growth path to exist in this model economy, the minimum consumption level $\alpha_{t}$ should grow at the same rate as per capita consumption along that path. Thus, calling $g$ the net rate of consumption growth along the balanced growth path, we will assume that

$$
\alpha_{t}=(1+g)^{t} \alpha \quad \text { for all } t=0, \ldots .
$$

Under this assumption this economy exhibits a balanced growth path where per capita income capital and household's consumption grow at the rate $g=(1+$ $\gamma)^{1 /(1-\theta)}-1$.

We have modelled the evolution of the subsistence consumption $\alpha_{t}$ in a very particular manner. We have assumed that the amount of consumption considered a "primary necessity" varies with the level of Total Factor Productivity. This assumption implies that the minimum consumption grows less rapidly than consumption and income along the transition path. This subsistence consumption can be thought of as consumption-based poverty line. The perception of this poverty line, or what amounts to the same, the level of consumption below which a person can be accounted for as poor, varies within and across countries. In this regard, the 1990 World Bank Report (pp. 26-27) says,

A consumption-based poverty line can be thought of as comprising two elements: the expenditure necessary to buy a minimum standard of nutrition and other basic necessities and a further amount that varies from country to country, reflecting the cost of participating in the everyday life of society. The first part is relatively straightforward. The cost of minimum adequate caloric intakes and other necessities can be calculated by looking at the prices of the foods that make up the diets of the poor. The second part is far more subjective; in some countries indoor plumbing is a luxury, but in others is a "necessity". 


\subsection{The determinants of the wealth distribution}

To analyze the determinants of wealth distribution we summarize some properties of the transitional dynamics of the class of economies studied. Solving the problem for household $i$ shown in (3), the household $i$ 's demand function is

$$
\begin{gathered}
\left.c_{t}^{i}=\alpha_{t}+\frac{1}{M_{t}} \sum_{s=t}^{\infty} \frac{p_{s}}{p_{t}}\left(w_{s}-\alpha_{s}\right)+\left(1+r_{t}\right) a_{t}^{i}\right), \\
M_{t}=\sum_{s=t}^{\infty} \beta^{(s-t) / \sigma}(1+n)^{(s-t) / \sigma}\left(\frac{p_{s}}{p_{t}}\right)^{(\sigma-1) / \sigma},
\end{gathered}
$$

where $p_{t}$ is the price of the consumption good in period $t$ in terms of consumption good in period 0. Eq. (7) says that the excess of consumption above $\alpha_{t}$ at period $t$ is the fraction $1 / M_{t}$ of life-time wealth net of future needs of consumption. Substituting the demand function shown in (7) in the household's budget constraint, we obtain the law of motion of household wealth:

$$
a_{t+1}^{i}=B_{t}+D_{t} a_{t}^{i},
$$

where

$$
\begin{aligned}
& D_{t}=\frac{1}{(1+n)}\left(1+r_{t}\right)\left(1-\frac{1}{M_{t}}\right), \\
& B_{t}=\frac{1}{(1+n)}\left[\left(w_{t}-\alpha_{t}\right)-\frac{1}{M_{t}} \sum_{s=t}^{\infty} \frac{p_{s}}{p_{t}}\left(w_{s}-\alpha_{s}\right)\right] .
\end{aligned}
$$

We can also express the per capita stock of capital, $k_{t}=K_{t} /(1+n)^{t}$, in terms of factors $B_{t}$ and $D_{t}$,

$$
k_{t+1}=B_{t}+D_{t} k_{t} .
$$

The household's consumption demand function is an affine function of its level of wealth. This implies that the evolution of aggregate consumption only depends on the evolution of aggregate capital and not on its distribution across households. For the same reason, the evolution of aggregate capital only depends on its level. This result is due to the specific utility function used and the existence of perfect capital markets. In this economy, as in Chatterjee (1994) or Caselli and Ventura (2000), the dynamics of the aggregate variables do not depend on the initial level of inequality and are identical to the dynamics of the representative agent version of this economy. Nevertheless, the evolution of the wealth distribution and the final distribution in the steady state will depend on the initial level of inequality and on the length of the transition path. We turn to analyze this point. 
Let us define $X_{t}^{i}$ as the ratio of household $i$ 's wealth (net worth) to aggregate capital, $X_{t}^{i}=a_{t}^{i} / k_{t}{ }^{2}$ Thus, the evolution of the ratio $X_{t}^{i}$ with respect to the average is given by

$$
X_{t+1}^{i}-1=\frac{D_{t} k_{t}}{B_{t}+D_{t} k_{t}}\left(X_{t}^{i}-1\right) .
$$

Expression (13) shows that the share $X_{t+1}^{i}$ approaches (deviates from) the average when the factor $D_{t} k_{t} /\left(B_{t}+D_{t} k_{t}\right)$ is smaller (greater) than one. The value of this ratio depends on the signs of the factors $B_{t}$ and $D_{t}$, which have ready economic interpretations. Factor $D_{t}$ is the fraction of current wealth after the return to capital has been paid that is not consumed at period $t$ and, therefore, is saved. Factor $B_{t}$ is the difference between the two terms. The first one is the amount of current labor income that exceeds $\alpha_{t}$. The second term is the fraction of present value of labor earnings above the minimum consumption requirement that finances excess consumption, $c_{t}^{i}-\alpha_{t}$, at period $t$. Hence, if $B_{t}<0$, households cannot finance current consumption with only current labor earnings and need to either use capital income, deplete their stock of capital or borrow. It is easy to check in expression (8) that $M_{t}$ is always greater than one along the transition path; therefore, factor $D_{t}$ is always positive. ${ }^{3}$ Factor $B_{t}$, however, can be either positive or negative. Thus, we can already postulate that the evolution of $B_{t}$ governs the evolution of the wealth distribution in this economy.

To analyze the evolution of the distribution of wealth we must first define the notion of inequality. We choose the definition of Lorenz-dominance, offered here in terms of our notation.

Definition 2. Let all households be ordered according to their initial level of wealth. Let $I$ be the number of types of households according to their level of wealth. $\frac{1}{I} X_{t}^{i}$ is the share of wealth held by group $i$. Then, the distribution of capital at period $t+1$ is more egalitarian than the distribution at period $t$ if and only if it is satisfied that for $1 \leqslant J \leqslant I$,

$$
\sum_{i=1}^{J} \frac{1}{I} X_{t+1}^{i} \geqslant \sum_{i=1}^{J} \frac{1}{I} X_{t}^{i}
$$

The following proposition relates the level of inequality of our model with its aggregate dynamics.

\footnotetext{
${ }^{2}$ We depart from Chatterjee (1994) who analyzes the evolution of life-time wealth, $\sum_{s=t}^{\infty}\left(p_{s} / p_{t}\right) w_{s}+$ $\left(1+r_{t}\right) a_{t}^{i}$. This definition of wealth is not very standard in the empirical studies. For instance, Wolff (1994) defines marketable wealth (or net worth) as the difference in value between total assets and total liabilities and debt. Since the purpose of this paper is to quantitatively assess the importance of differences in saving rates across households to understand the evolution of wealth inequality, we prefer to use a measure of wealth that can be readily compared to the data.

${ }^{3}$ The factor $p_{s} / p_{t} \beta^{s-t}$ is always less than one along a transition path that starts with a level of capital smaller than the steady state level of capital. Hence, factor $M_{t}$ is always greater than one and decreases monotonically along the transition path. See Chatterjee (1994).
} 
Proposition 1. The distribution of capital at period $t+1$ is more egalitarian than the distribution of wealth at period $t$ if and only if $B_{t}$ is nonnegative.

Proof. See Appendix.

This Proposition states that in order to know the evolution of the wealth distribution over time we just need to study the evolution of $B_{t}$.

We can investigate further the determinants of the evolution of factor $B_{t}$. It is easy to check that along the balanced growth path the value of factor $B_{t}$ is zero. Thus for the class of economies considered here the wealth distribution remains invariant along that path. After some algebra (see Appendix) we can express this factor as a function of the path of aggregate consumption, aggregate income and the aggregate savings rate:

$$
B_{t}=\frac{M_{t}\left((1-\theta) y_{t}-\alpha_{t}\right)}{1+n} \sum_{s=t}^{\infty} \frac{p_{s}}{p_{t}} \frac{c_{s}-\alpha_{s}}{c_{t}-\alpha_{t}}\left[1-\frac{\frac{\left(1-x_{t}\right) y_{t}-\alpha_{t}}{(1-\theta) y_{t}-\alpha_{t}}}{\frac{\left(1-x_{s}\right) y_{s}-\alpha_{s}}{(1-\theta) y_{s}-\alpha_{s}}}\right],
$$

where $y_{t}$ denotes per capita income, $c_{t}$ is per capita consumption, $x_{t}$ denotes aggregate saving rate and $\theta$ is the share of capital in production. Thus, the evolution of factor $B_{t}$ depends on the evolution of aggregate income, which is independent of the level of inequality, as well as the evolution of the aggregate saving rate, which does depend on the wealth distribution. We will discuss this point more thoroughly in the following sections.

Now we turn to analyzing the properties of the Gini coefficient.

Corollary 1. The Gini coefficient at any period $t$ depends on the initial distribution and the evolution of aggregate capital,

$$
G_{t+1}=\prod_{r=0}^{t}\left(\frac{D_{r} k_{r}}{B_{r}+D_{r} k_{r}}\right) G_{0} .
$$

Proof. See Appendix.

This Corollary states that the evolution of the level of inequality is invariant with respect to the initial level of inequality, as measured by the Gini coefficient. ${ }^{4}$ The absolute magnitude of the level of inequality does depend on its initial level, however. Moreover, the length of the transition path is key to observing any change in wealth inequality.

\section{Historical evidence}

The existing data on the evolution of the wealth distribution in the U.S. over the period 1870-1970 is highly fragmented but nonetheless offers some general guidance

\footnotetext{
${ }^{4}$ The same applies to the coefficient of variation. The evolution of this index of inequality would also depend on the evolution of capital and the initial level of inequality.
} 
about the evolution of inequality over time. The studies that most thoroughly analyze the data available for that period are Lindert (2000) and Williamson (1991).

The evolution of wealth inequality in the late 19th and early 20th centuries appears to be controversial. Williamson (1991) reports that in 1870 the top 1 percent of all adults held 27 percent of total assets in the U.S., whereas the top 10 percent held 70 percent. The associated Gini coefficient was 0.83 . Since that time until the years after World War II there is a gap that some authors have filled with fragmentary data. Tables 5 and 6 contain data from Lindert (2000) which give us some idea of the evolution of inequality. These tables show the net worth held by the top 1 percent of individuals for selected years within the period 1890-1989. This group held 25.8 percent of total wealth in 1890, with the share peaking somewhere between 1913 and 1929 and remaining largely stable around 30 percent until the early 1970s. After a short downturn in this share during the early 1970s, it again rises to a six-decade high in 1989. These observations are in line with the documented rise in wealth inequality after the 1970s (see, for instance, Wolff, 1994).

There is a gap in the data between 1890 and 1922. Lindert, 2000 proposes that inequality in America in 1929 was roughly the same as in England at that time. $\mathrm{He}$ also reports that the share of marketable net worth held by the top 5 percent of all adults was 78.9 in that year. This data combined with the data for the U.S. in 1870 suggests that wealth inequality increased in the period 1870-1929. However, it is important to bear in mind the fragility of the evidence handled for this period. While there is strong evidence for an increase in wealth inequality in the period, exactly how pronounced and when it began is still a hotly debated issue.

Many authors (e.g., Atkinson, 1997) have pointed out the remarkable stability of wealth and income distribution of the U.S. economy during the post-WWII period. Tables 8 and 9 show the U.S. wealth distribution in 1962 and 1989. The data on the 1962 distribution are taken from Wolff (1994) and the data for 1989 are taken from the 1989 Survey of Consumer Finances. Both distributions are very similar. In 1962 the share of wealth of the top decile was 66.90 percent while it was 67.29 in 1989, a little bit lower than its value in 1870 . The Gini coefficient for wealth in 1989 was 0.79 , whereas it was 0.83 in 1870 .

In summary, we can say that the historical evidence suggests an increase of inequality during the early 20th century and a long period of steady inequality after World War II. If we take the share held by the top 10 percent of households as an inequality indicator, the magnitude of the variation in inequality has been modest, although this overall level may hide transitional changes along the period 1870-1970, as Lindert (2000) suggests. We will use this evidence to assess the quantitative significance of differences in saving rates across households to account for the evolution of the wealth distribution in the U.S. over the period 1870-1970.

\section{Calibration}

In this section we discuss the calibration of our model economy. We proceed in two steps. Section 4.1 describes the calibration of the technology and the preference 
parameters. We select parameter values so that the aggregate statistics of the balanced growth path of our model economy match some key features of the U.S. economy. In Section 4.2 we discuss our choice for the initial distribution of wealth across households.

\subsection{Calibration of the representative agent version of the model economy}

We focus our study on the period 1870-1970. We assume that the U.S. economy is on its balanced growth path throughout the period 1950-1970. To calibrate our model economy we use data from the National Income and Product Accounts (NIPA) and Fixed Reproducible Assets published by the Bureau of Economic Analysis for the years 1950-1970. First of all we construct measures of output, $Y$, investment, $I$, and aggregate capital, $K$, consistent with our theory. We define output as measured GDP plus the estimated value of the flow of services of consumer durable goods. The stock of capital is the sum of private fixed assets, the stock of inventories and the stock of consumer durables. Aggregate investment is the sum of investment in private assets plus the change in inventories, net exports and durable expenditures.

Other authors, such as Cooley and Prescott (1995), include government owned capital as part of the aggregate stock of capital and, therefore, augment our definition of output with the imputed flow of services of this capital. We have decided not to include government owned capital because the focus of this paper is on the distribution of privately owned wealth. The average capital-output ratio for the period $1950-1970$ is 2.42 , whereas the investment-capital ratio is 0.09 . Using the procedure outlined by Cooley and Prescott (1995) we obtain a capital share of 0.34 . The rate of population growth, $n$, is set equal to 1 percent per year. Furthermore, we set the initial level of Total Factor Productivity $z$ equal to 1.

We need to choose an appropriate value for $\gamma$, the Total Factor Productivity growth rate. Since we want the transitional dynamics of the model to mimic some features of the U.S. economy the choice of $\gamma$ has to be consistent with the accumulated growth in per capita income observed within the period covered in this paper. According to Maddison (1982) real per capita GDP was 7 times higher in 1970 than 1870. King and Rebelo (1993), who study the transitional dynamics of the neoclassical growth model, assume that Total Factor Productivity growth explains one half of the sevenfold per capita output growth observed within the period 1870-1970. Gordon (2000) reports growth rates for non-farm, non-housing business GDP, capital, and labor for the periods 1870-1913, and 1913-1972 (see Table 1 in the paper). Using that data, we calculate that non-farm non-housing business GDP has been multiplied by about a factor of 12.62 within the period $1870-1972 .{ }^{5}$ Using our share of capital and the growth rates he reports we can calculate the implied Total Factor Productivity growth rate. Our calculations show that, in absence of any

\footnotetext{
${ }^{5}$ According to Maddison (1987), average annual GDP per capita growth was 4.20 for the period 1870-1913 and 3.14 for the period 1913-1973. This suggests a total growth factor higher than 7 for the period 1870-1970 assumed in this paper, consistent with Gordon's (2000) reported rates. We prefer the widely accepted factor of 7 assumed in the literature, although this may imply lower growth rates for the aforementioned periods.
} 
Table 1

Technology parameter values

\begin{tabular}{lllll}
\hline$n$ & $z$ & $\theta$ & $\delta$ & $g$ \\
\hline 0.0100 & 1.0000 & 0.3433 & 0.0663 & 0.0148 \\
\hline
\end{tabular}

input growth, GDP would have multiplied by 3.98 within that period. In other words, Total Factor Productivity explains about one half of the observed growth in per capita output. Thus, we assume in our benchmark calibration that total factor productivity explains one half of the observed output growth. In Section 6.1 we discuss the quantitative implications of assuming a different contribution of Total Factor Productivity. Thus, we set the annual growth rate of Total Factor Productivity (TFP, hereafter) so that

$$
(1+\gamma)^{100}=7^{0.5} .
$$

We find that $\gamma=0.0097$. This implies a balanced path growth rate $g$ equal to 1.48 percent. As do King and Rebelo (1993), we choose an initial level of capital so that

$$
\frac{k_{1970}^{\theta}}{k_{1870}^{\theta}}=7^{0.5} .
$$

Growth in capital is affected by TFP growth, so we derive de-trended variables such that the expression above can be written as

$$
(1+g)^{100 \theta} \frac{\widehat{k}_{1970}^{\theta}}{\widehat{k}_{1870}^{\theta}}=7^{0.5} .
$$

Since we assume that by 1970 the U.S. economy had reached its balanced growth path, the de-trended value of capital $\widehat{k}_{1970}$ should be equal to the steady state capital in the model without TFP growth. Proceeding in this way we find a value for the initial stock of capital, $\widehat{k}_{1870}$, equal to 25.28 percent of the (de-trended) level of capital in steady state. We summarize the calibrated parameters in Table 1.

Finally, we need to set values for the minimum consumption requirement as well as the risk aversion parameter $\sigma$. Atkeson and Ogaki (1996) estimate a value of the intertemporal elasticity of substitution for aggregate consumption expenditures in the U.S. economy equal to 0.4 for the period 1968-1988. Thus we take 0.4 as the value of the aggregate IES, in the steady state. Recall that per capita consumption and the minimum consumption grow at the same rate $g$. Thus, by de-trending variables we can compute the IES in the steady state:

$$
\mathrm{IES}=\frac{\widehat{c}_{s s}-\alpha}{\sigma \widehat{c}_{s s}}=0.4,
$$

where $\widehat{c}_{s s}$ denotes de-trended steady state aggregate per capita consumption. Since we have assumed $\alpha$ to be nonnegative, Eq. (20) imposes an upper bound for $\sigma$ : it has to be less than or equal to 2.5 . We also believe it reasonable to impose that $\alpha / \widehat{c}_{s s}$ 
Table 2

Preferences parameter values

\begin{tabular}{llllr}
\hline & $\sigma$ & $\alpha$ & $\beta$ & $\alpha / \widehat{c}_{s s}$ \\
\hline High minimum consumption & 1.50 & 0.4948 & 0.9504 & 0.4000 \\
Low minimum consumption & 1.80 & 0.3463 & 0.9546 & 0.2800 \\
Neoclassical & 2.50 & 0.0000 & 0.9645 & 0.0000 \\
\hline
\end{tabular}

should not be greater than 0.4 . These considerations restrict the region of values of $\sigma$ to $[1.5,2.5]$. We will in the following analyze three different model economies reflecting different values of $\sigma, 1.50,1.80$, and 2.5. The last case corresponds to the standard neoclassical model with homothetic preferences. In each case the value of $\alpha$ is chosen so that (20) holds. Table 2 shows that the level of minimum consumption as a fraction of steady state consumption is lower the higher the value of $\sigma$. This is because $\alpha$ is calibrated so that the IES for aggregate consumption is 0.4 in the steady state. ${ }^{6}$ In other words, IES for aggregate consumption along the balanced growth path is kept the same for all three model economies. Any differences among the three economies thus arise from the different behavior of the IES across households and, hence, from the differences in their saving rates along the transition path. We will call the model economy for which $\sigma=1.50$ the high minimum consumption economy, the economy where $\sigma=1.80$ the low minimum consumption economy and the last one the neoclassical economy.

\subsection{Calibration of the initial wealth distribution}

We calibrate the initial wealth distribution across deciles so that it reproduces the Gini coefficient and the share of the top 10 percent of households reported by Williamson (1991) for $1870 .^{7}$ The distribution chosen is shown in Table 7 on the row named Benchmark. In principle, there are many distributions that match Williamson's data; for instance, the U.S. in 1989. This is why we also report results of a second experiment using it as the initial distribution.

\section{Quantitative implications of the model}

We have seen in the previous section that the aggregate behavior of the economy along the transition path is not affected by the level of wealth inequality. This allows us to study our three model economies in two steps: we analyze the evolution of

\footnotetext{
${ }^{6}$ To give an idea of what the fraction $\alpha / \widehat{c}_{s s}$ represents, we have computed the amount of food expenditures as a fraction of nondurable consumption expenditures using the National Income and Product Accounts for the period 1949-1970. This fraction decreases over time, from 21.0 in 1949 to 15.6 percent in 1949.

${ }^{7} \mathrm{We}$ are aware that the individual wealth distribution is different from the household wealth distribution, but we do not have other inequality data for that year. Thus, we take Williamson's data as an approximation to the level of household wealth inequality.
} 
prices and aggregate variables in their representative agent version in Section 5.1 and in Section 5.2 we study the evolution of their wealth distribution.

\subsection{Aggregate dynamics}

In this subsection we examine the properties of the transitional dynamics of the representative agent version of our model economies. Fig. 1 shows the evolution of gross aggregate saving rate, the real interest rate, the output growth rate and the factor $B$ along the transition path. In the three model economies, output reaches 0.99 percent of its value in the steady state after 44 periods for the high minimum consumption economy, 43 for the low minimum consumption economy and 42 for the neoclassical economy. Thus, the transition is mostly completed by 1913 . Table 3 shows the average output growth rate for selected periods. There are not remarkable differences for the three economies. Average growth rate for the period 1870-1913 is about 2.56 percent, falling to 1.50 percent for the period 1900-1970. Maddison (1987) reports average growth rates for those periods of 4.20 and 3.14 percent, respectively. Similar rates are reported by Gordon (2000). Our rates diverge from the rates estimated by these authors because we assume a sevenfold growth in GDP per capita and a constant rate of growth of TFP. Nevertheless, the overall pattern of
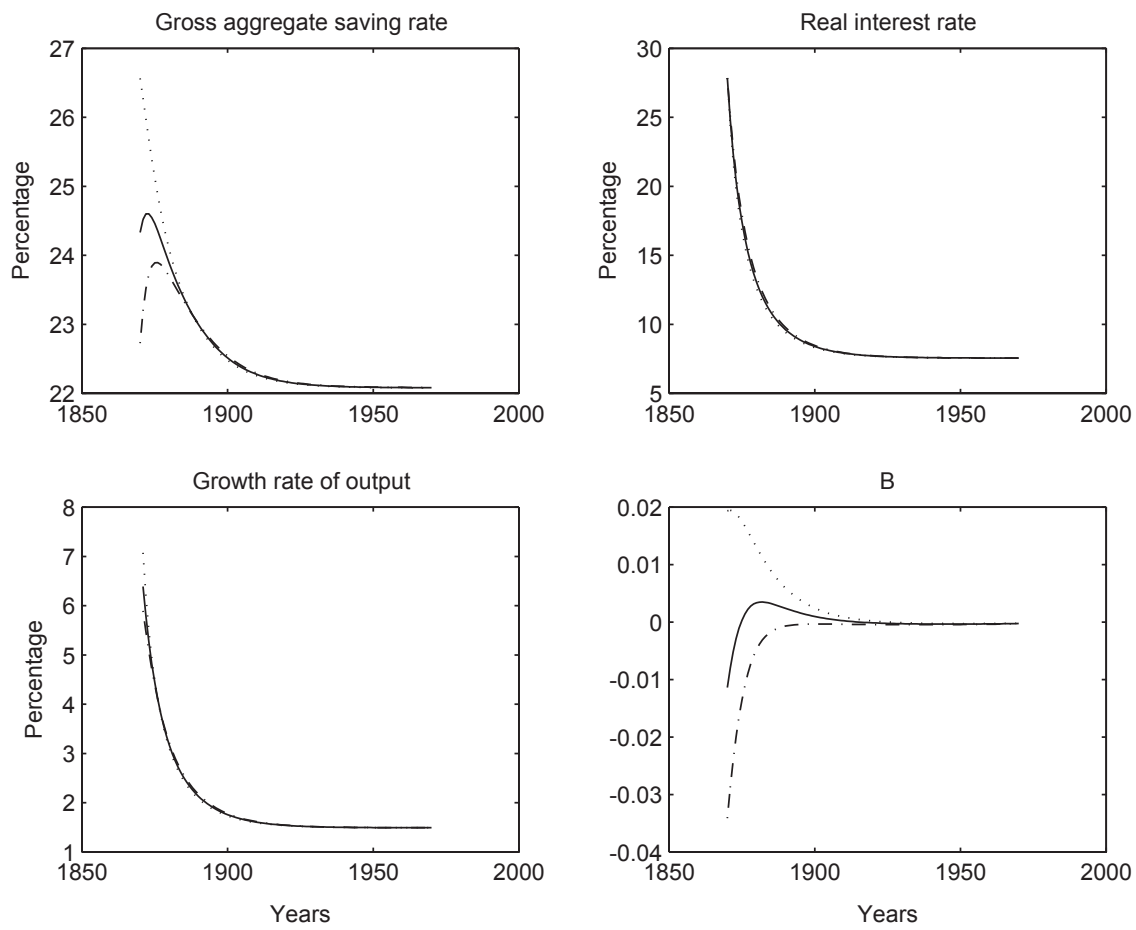

Fig. 1. Evolution of gross saving rate, real interest rate, growth rate of output and factor $B$ along the transition path. Solid line, $\sigma=1.80$, dotted line, $\sigma=2.50$ and dashed-dotted line $\sigma=1.50$. 
Table 3

Output growth rates for selected periods

\begin{tabular}{llll}
\hline & $1870-1900$ & $1870-1913$ & $1913-1970$ \\
\hline High minimum consumption & 2.91 & 2.54 & 1.51 \\
Low minimum consumption & 2.92 & 2.54 & 1.51 \\
Neoclassical & 2.93 & 2.55 & 1.51 \\
Maddison (1987) & - & 4.20 & 3.14 \\
\hline
\end{tabular}

Table 4

Aggregate gross saving rate for selected periods (\%)

\begin{tabular}{llr}
\hline & 1870 & 1900 \\
\hline High minimum consumption & 22.73 & 22.54 \\
Low minimum consumption & 24.33 & 22.51 \\
Neoclassical & 26.57 & 22.48 \\
Williamson (1991) & 23.00 & 28.00 \\
\hline
\end{tabular}

output growth in our artificial economies resembles that found by these authors: higher growth in the period 1870-1913 than in the subsequent period. In other words, it is reasonable to assume that the U.S. economy was not on a balanced growth path before 1913. This is important since all the changes in wealth distribution in our model stem from its transitional dynamics.

Table 4 shows that the economy with the highest saving rate is the neoclassical economy while the high minimum consumption economy exhibits the lowest saving rate. The third model lies in between. Williamson (1991) reports that the gross saving rate was 23 percent in 1870 , rising to 28 percent by the turn of the century. The saving rate for each case in the initial period is 22.73 percent for the high minimum consumption economy, 24.33 percent for the low minimum consumption economy and 26.57 percent for the neoclassical economy; for all economies gross saving fall to around 22 percent at the turn of the century.

Williamson also reports that the return to conventional reproducible assets was 6.6 percent at the turn of the century. The evolution of the real interest rate is very similar in the four cases considered. It starts being 27.86 percent and drops to around 8 percent after 30 periods (which corresponds to the year 1900 in our model). Thus, the interest rate is higher in the model than in the data. Nevertheless, we should keep in mind that the interest rate of our model economy has no counterpart in the U.S. economy, since we are assuming that aggregate capital includes consumer durables.

Thus, the model economies display very similar evolution of all aggregate variables save factor $B_{t}$. Fig. 1 shows that in the neoclassical economy $B_{t}$ is always positive and falls steadily to zero along the transition path. This implies that wealth inequality should decrease monotonically in the neoclassical economy. The opposite occurs in the high minimum consumption economy: here $B_{t}$ is always negative while 
approaching to zero monotonically. Thus, wealth inequality should always increase. In the low minimum consumption economy factor $B_{t}$ starts out negative, becomes positive and falls to zero afterwards. In this case the evolution of the wealth distribution has an inverted $U$ shape. The next section will consider how much variation in inequality this model generates along the transition path.

\subsection{The evolution of inequality}

In this subsection we analyze the size of the variation in inequality generated along the transition path and confront our results with the available evidence about the evolution of the U.S. wealth distribution (Tables 5-7).

\subsubsection{The neoclassical economy}

The upper left panel of Fig. 2 shows the evolution of the Gini coefficient for wealth. As we can see, its initial value is 0.83 , falling to 0.72 in the steady state. Recall from the previous section that the transition to steady-state was mostly completed by 1913; yet here we see some changes in the Gini coefficient for wealth after 1913. The reason for this behavior is that the economy approaches its balanced growth path monotonically. After 1913 there are only minimal differences between the simulated path of output and its value along the balanced growth path. This slight difference accounts for the minimal changes in the savings rates across households after 1914 (period 44 in the model economy); this deviation in the savings rates is responsible for the small changes in wealth inequality after that period. This applies to all the model economies studied.

The upper panels of Tables 8 and 9 present some statistics that summarize the steady state wealth distribution of our three model economies; the 1962 U.S.

Table 5

Wealth inequality in the U.S., 1890-1962

\begin{tabular}{lcccccrrrr}
\hline \multicolumn{1}{c}{ Net worth held by top $1 \%$ of households, $1890-1962$} \\
\hline Years & 1890 & 1922 & 1929 & 1933 & 1939 & 1945 & 1949 & 1953 & 1962 \\
Share (\%) & 25.8 & 36.7 & 44.2 & 33.3 & 36.4 & 29.8 & 27.1 & 31.2 & 31.8 \\
\hline
\end{tabular}

Source: Lindert (2000).

Table 6

Wealth inequality in the U.S., 1965-1989

\begin{tabular}{lccccccrrr}
\hline \multicolumn{1}{c}{ Net worth held by top $1 \%$ of households, $1965-1989$} \\
\hline Years & 1965 & 1969 & 1972 & 1976 & 1979 & 1981 & 1983 & 1986 & 1989 \\
Share (\%) & 34.4 & 31.1 & 29.1 & 19.9 & 20.5 & 24.8 & 30.9 & 31.9 & 35.7 \\
\hline
\end{tabular}

Source: Lindert (2000). 
Table 7

Initial distribution of wealth

\begin{tabular}{lrlllllllll}
\hline \multicolumn{10}{c}{ Deciles (Share \%) } \\
\cline { 2 - 10 } & 1st & 2nd & 3rd & 4th & 5th & 6th & 7th & 8th & 9th & 10 th \\
\hline Benchmark & 0.10 & 0.53 & 0.59 & 0.90 & 1.01 & 3.17 & 5.40 & 8.09 & 10.10 & 70.09 \\
U.S. 1989 & -0.51 & 0.04 & 0.30 & 0.93 & 1.92 & 3.26 & 5.12 & 7.93 & 13.65 & 67.29 \\
\hline
\end{tabular}
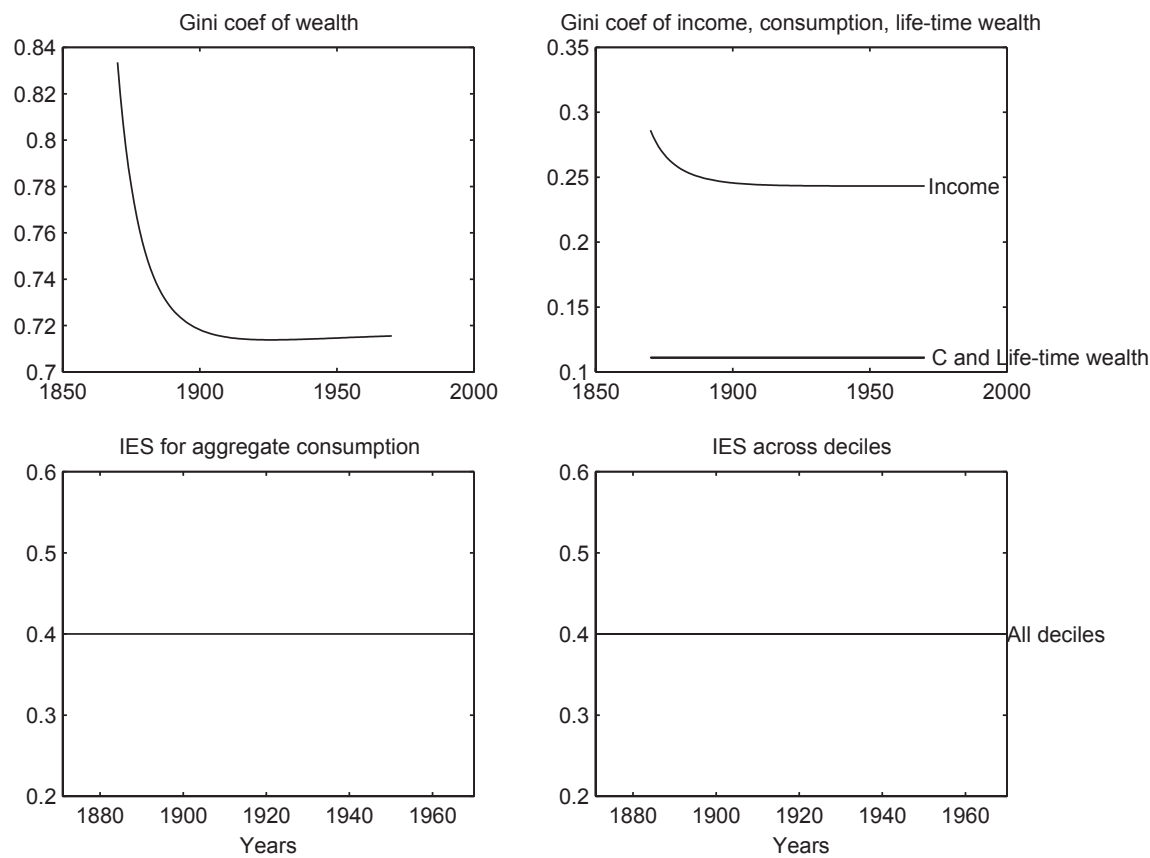

Fig. 2. Evolution of inequality, $\sigma=2.50$.

distribution of wealth is included for comparison. We use the 1962 distribution as a proxy for the 1970 distribution since we do not have full information about the distribution across deciles in 1970. Table 8 (upper panel) shows that the share of wealth held by the top quintile is much lower than in the data, whereas the shares held by the two bottom quintiles are significantly higher. Thus, the neoclassical economy fails to reproduce the 1962 wealth distribution across quintiles. Better results are achieved when the top decile of the distribution is considered. Table 9 (upper panel) shows that the share of the top decile is 61.58 percent, whereas it is 66.90 in the data; however the bottom 80 percent of households still holds a fraction of wealth much higher than in the data. Thus, wealth inequality declines much more in the model relative to what we see in the data. 
Table 8

Wealth distribution along the balanced growth path

\begin{tabular}{|c|c|c|c|c|c|c|}
\hline & & \multicolumn{5}{|c|}{ Quintiles (Share \%) } \\
\hline & & $1 \mathrm{st}$ & $2 \mathrm{nd}$ & $3 \mathrm{rd}$ & 4 th & 5 th \\
\hline \multirow[t]{3}{*}{ Benchmark } & High minimum consumption & -2.14 & -1.15 & 1.92 & 12.56 & 88.81 \\
\hline & Low minimum consumption & 0.57 & 1.43 & 4.13 & 13.47 & 80.41 \\
\hline & Neoclassical & 3.37 & 4.11 & 6.42 & 14.41 & 71.67 \\
\hline Data & U.S. 1962 & -0.70 & 1.00 & 5.40 & 13.40 & 81.00 \\
\hline \multirow[t]{3}{*}{ U.S. 1989} & High minimum consumption & -3.39 & -1.45 & 3.06 & 12.07 & 89.71 \\
\hline & Low minimum consumption & -0.54 & 1.17 & 5.14 & 13.06 & 81.19 \\
\hline & Neoclassical & 2.43 & 3.89 & 7.28 & 14.04 & 72.36 \\
\hline Data & U.S. 1989 & -0.47 & 1.23 & 5.18 & 13.05 & 80.98 \\
\hline
\end{tabular}

Table 9

Wealth distribution along the balanced growth path

\begin{tabular}{lllll}
\hline & & \multicolumn{2}{l}{ Share $(\%)$} & \\
\cline { 3 - 5 } & & Bottom $80 \%$ & 2nd $10 \%$ & Top $10 \%$ \\
\hline \multirow{2}{*}{ Benchmark } & High minimum consumption & 11.19 & 10.14 & 78.67 \\
& Low minimum consumption & 19.60 & 10.12 & 70.28 \\
Data & Neoclassical & 28.32 & 10.10 & 61.58 \\
& U.S. 1962 & 19.10 & 14.00 & 66.90 \\
U.S. 1989 & & & & 75.50 \\
& High minimum consumption & 10.29 & 14.18 & 67.52 \\
Data & Low minimum consumption & 18.81 & 13.67 & 59.21 \\
\hline
\end{tabular}

The upper right panel of Fig. 2 shows the evolution of the Gini coefficient for income, consumption and lifetime wealth. We include the latter two coefficients in order to compare our qualitative results with those reported by Chatterjee (1994). A s he shows, with homothetic preferences the distribution of lifetime wealth is invariant along the transition path. Moreover, the distribution of consumption mirrors it exactly. Both distributions exhibit exactly the same level of inequality. Nevertheless, wealth inequality decreases over time: this is because savings rates differ across households. Fig. 3 shows that at the beginning of the transition path the poorer households' saving rate increases over time, whereas that of wealthier households decreases. Later on, poorer households also decrease their saving rate but at slower pace than wealthier households. Why this different behavior of saving rates? With homothetic preferences all households are willing to substitute current for future 

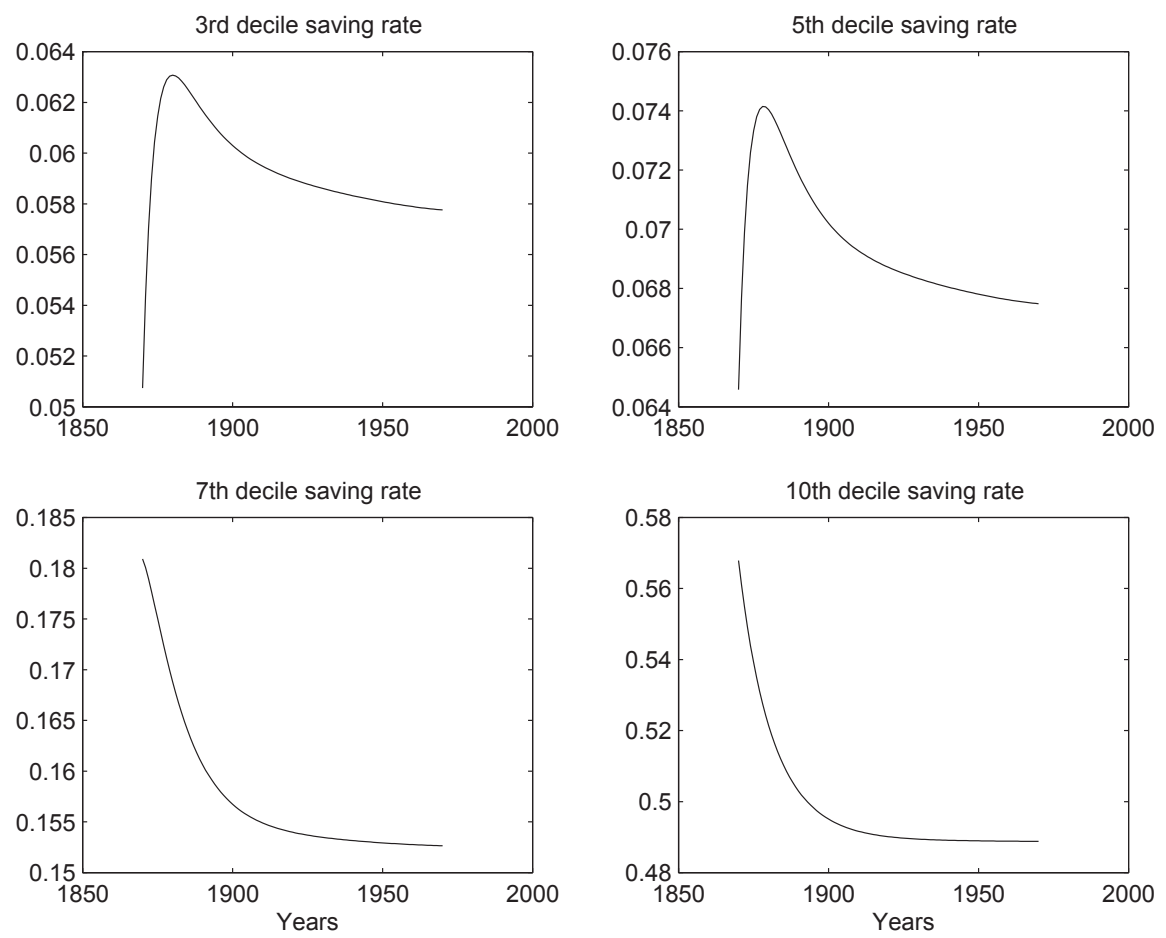

Fig. 3. Saving rates across deciles, $\sigma=2.50$.

consumption at the same rate. For the calibrated value of the risk aversion parameter $\sigma$ this rate is sufficiently high so that consumption at the beginning of the transition path is very low (compared to its steady state value). This implies very high income growth, more than average for wealthy households and below average for poor households. Thus, wealthy households have to decrease their saving rate if their consumption is to grow as quickly as the average. Poor households, on the other hand, must increase their saving rate; they do so at a faster pace than wealthy households decrease theirs. Thus, inequality decreases very quickly at the beginning. Later on, when aggregate income is sufficiently high poor households start decreasing their saving rate, but at a smaller rate than wealthy households do; thus inequality decreases more slowly until the economy reaches its steady state, whereupon savings become stable.

\subsubsection{The low minimum consumption economy}

Now we turn to analyzing the low minimum consumption economy. Fig. 4 shows the evolution of the various indices of inequality as well as the evolution of the IES for several types of households and the IES for aggregate consumption. Income inequality decreases along the transition path, whereas that of consumption increases. As Chatterjee (1994) shows, life-time inequality increases along the 

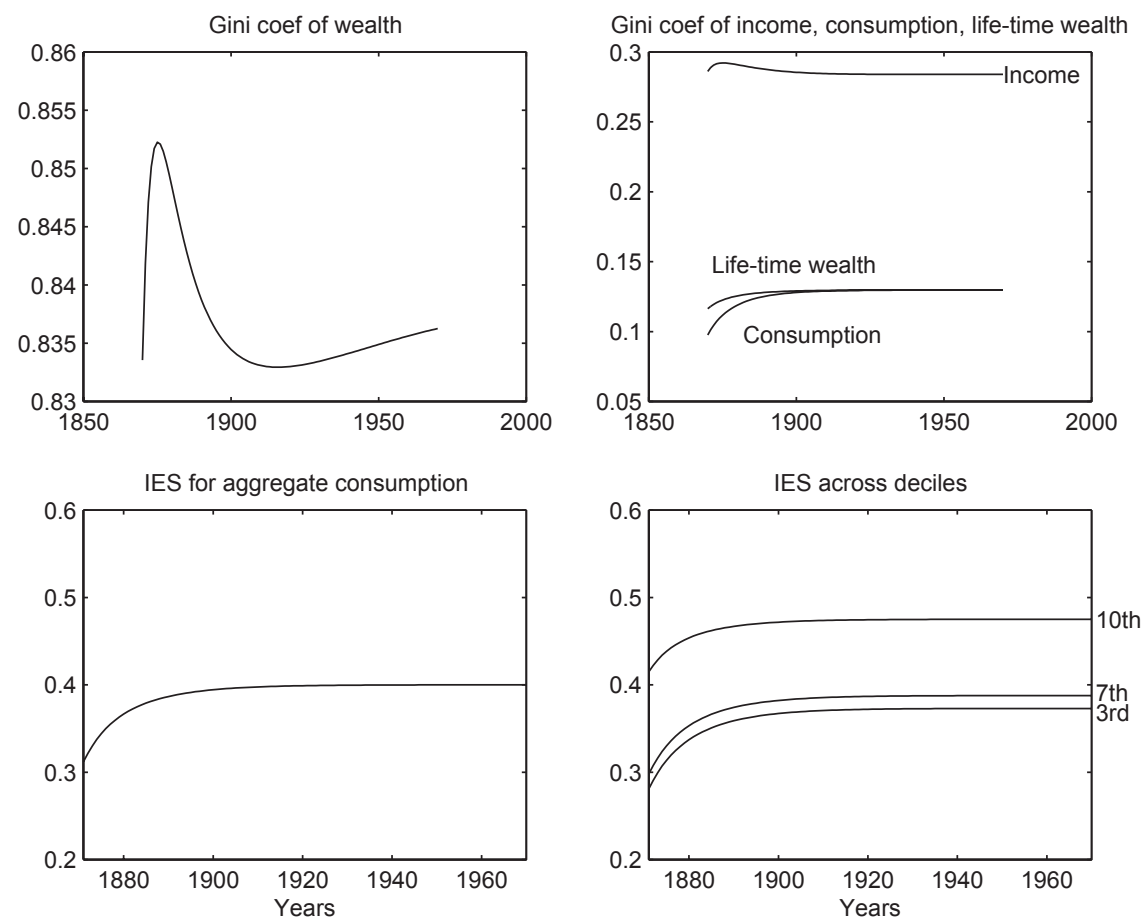

Fig. 4. Evolution of inequality, $\sigma=1.80$.

transition path. Wealth inequality, however, evolves in a very different manner, peaking very early in the transition and falling monotonically afterwards. Nonhomothetic preferences imply a behavior of saving rates different from the neoclassical case. Comparing Figs. 3 and 5 we see that the saving rate of households in the top decile of the wealth distribution is always higher than in the neoclassical economy. The reverse is true for the other deciles. This occurs because the existence of a minimum consumption level implies that poor households' IES is smaller than that of wealthier households. Thus, the rate at which poor households are willing to substitute current for future consumption is lower than that of wealthier households. This difference in IES across households is responsible for the different behavior of saving rates: as in the neoclassical economy, at the beginning of the transition poorer households increase their saving rate but now at a slower pace than wealthier households decrease theirs. As a result, inequality increases. After some periods wealthier households decrease their saving rate at a faster pace than poorer households do so that overall wealth inequality decreases.

Table 8 shows that the wealth distribution across quintiles in the balanced growth path reproduces that of the U.S. wealth for 1962 reasonably well and Table 9 shows that the share of the bottom 80 percent in the model is very close to that seen in the data. 

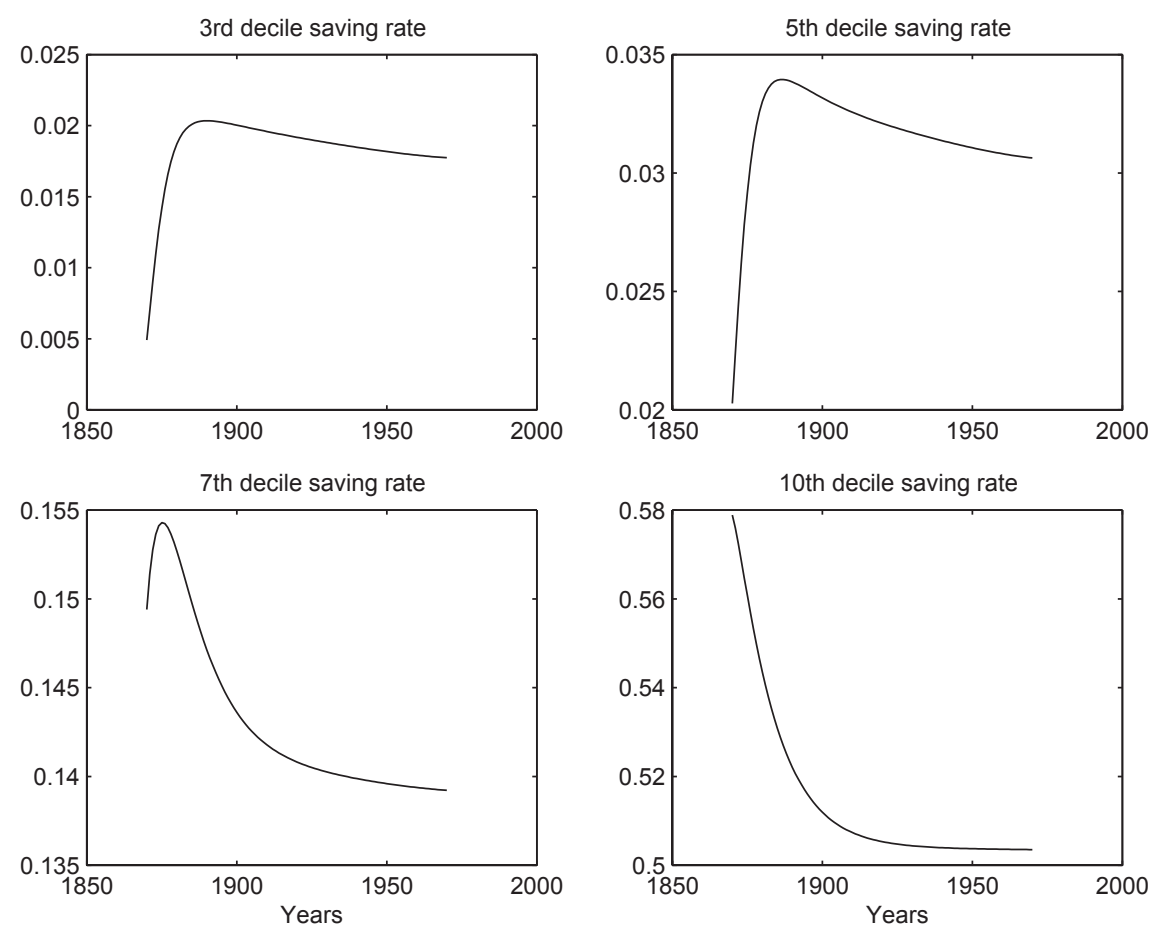

Fig. 5. Saving rates across deciles, $\sigma=1.80$.

\subsubsection{The high minimum consumption economy}

Fig. 6 shows the evolution of the various indices of inequality as well as the evolution of the IES for selected types of households and the IES for aggregate consumption. All indices of inequality increase along the transition path. The reason is illustrated in Fig. 7. At the beginning of the transition poorer households actually decrease their saving rate to maintain a smooth consumption path. This drives wealth inequality up. Afterwards, they increase their saving rate, but not at a fast enough pace so that wealth inequality keeps increasing. In other words, the effects described above for the low minimum consumption economy are amplified here, resulting in ever-increasing inequality.

Table 8 shows that the wealth distribution across quintiles in the steady state is much more unequal than that observed in 1962. For instance, the model predicts that the top 20 percent of households hold 88.81 percent of all assets, where it was 81 percent. Table 9 shows that the bottom 80 percent of households hold 11.19 percent of total wealth where it was 19.10 percent in the data.

\subsubsection{The importance of the savings channel}

The lower panel of Tables 8 and 9 show the steady state distribution of our three model economies obtained when we calibrate the initial wealth to match that of the 

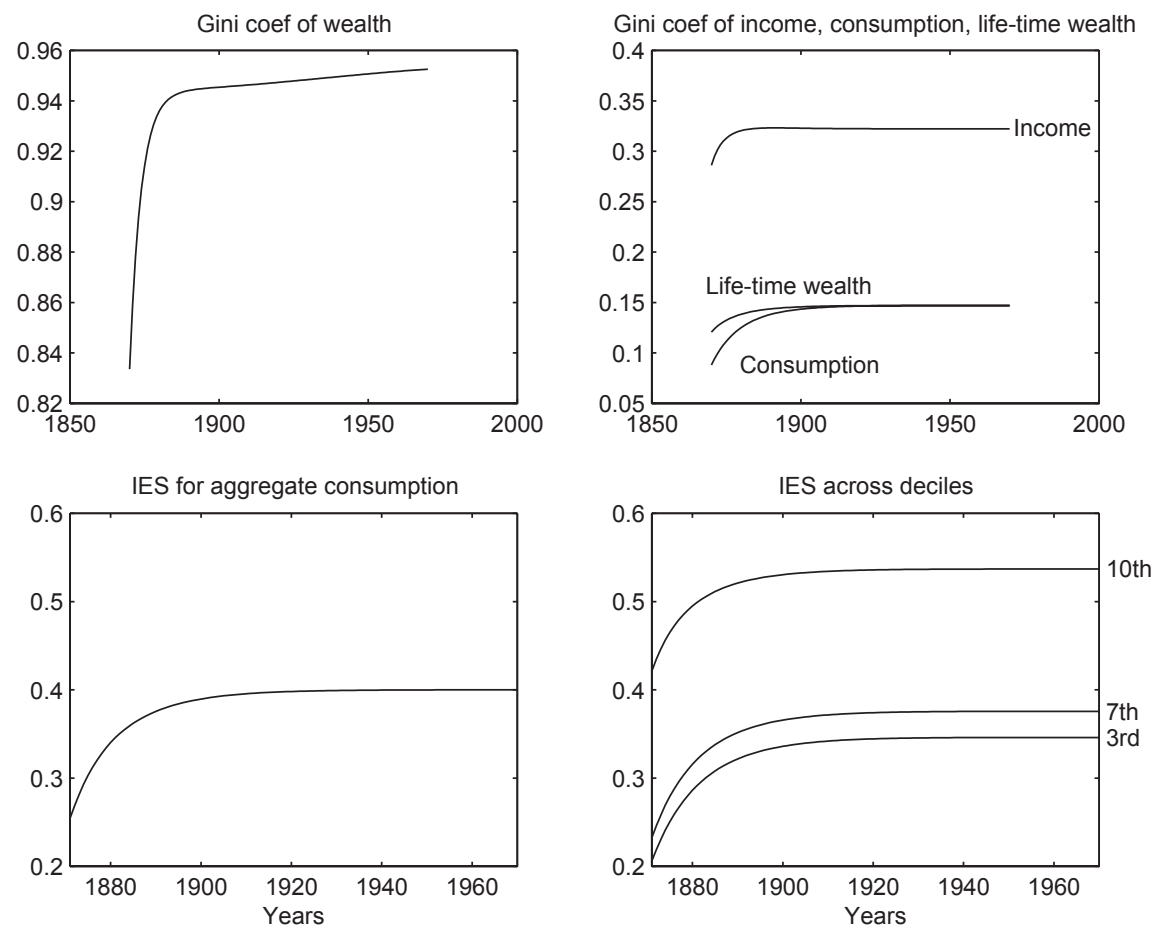

Fig. 6. Evolution of inequality, $\sigma=1.50$.

U.S. economy in 1989. Recall that the U.S. 1989 distribution reproduces the statistics of the 1870 distribution reported by Williamson (1991). The idea behind this experiment is the following: if differences in saving rates across households do not significantly affect the transitional dynamics of the wealth distribution, the three model economies should display very similar distributions along the balanced growth path. Moreover, the distribution along their balanced growth paths should be very similar to the assumed initial distribution. In such a case the way the initial differences in wealth holdings are propagated through time is trivial: the level of initial inequality would be perpetuated. On the contrary, if the wealth distribution evolves differently through time in each model economy and the evolution of wealth inequality in one of them mimics the observed pattern in the U.S. we could conclude that the saving rates channel is a significant mechanism through which initial wealth holding differences are propagated through time.

As we can see in those figures only the low minimum consumption economy reproduces the U.S. 1989 distribution reasonably well. Thus, we conclude that savings is an important factor in understanding the evolution and level of wealth inequality. 

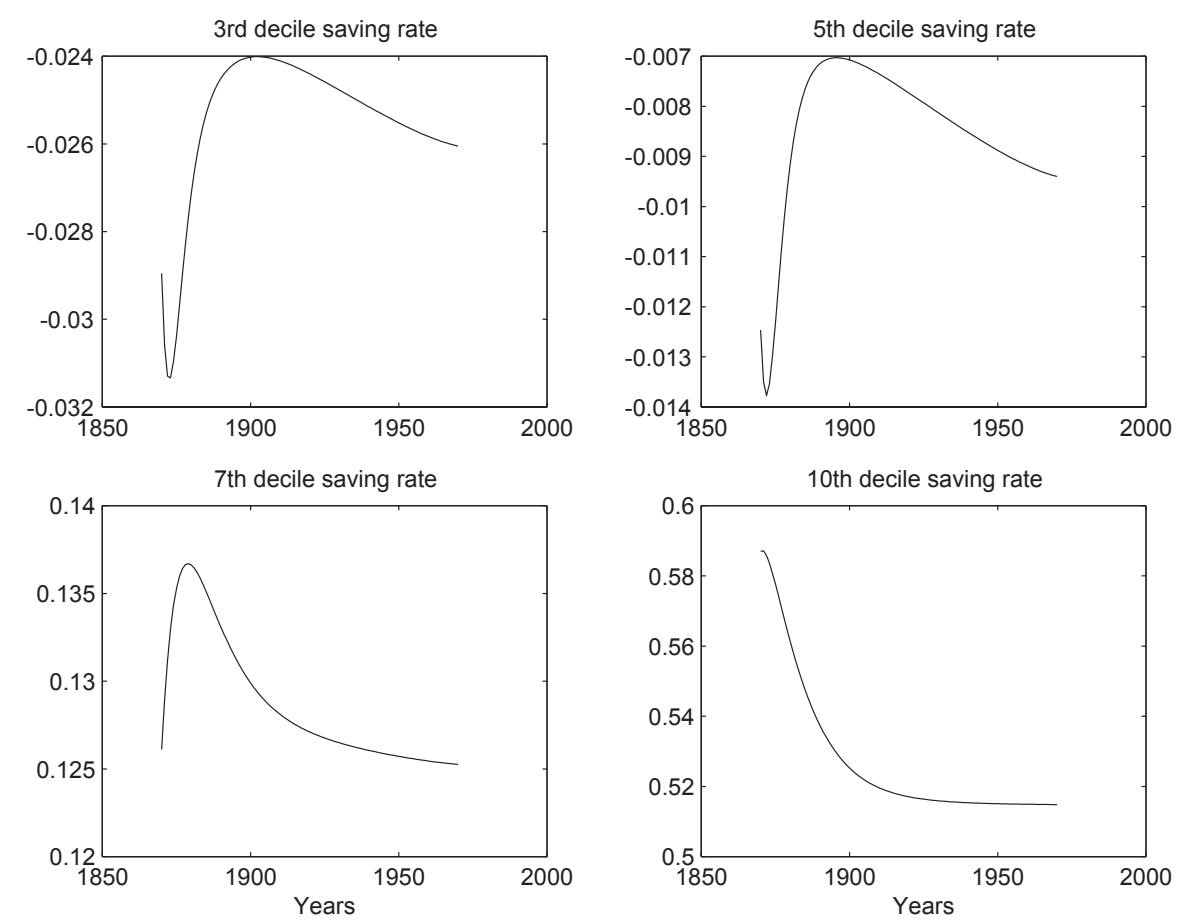

Fig. 7. Saving rates across deciles, $\sigma=1.50$.

\subsection{Discussion of the results}

Two lessons can be drawn from the previous analysis. First, similar aggregate behavior across economies may hide very different underlying dynamics in the distribution of wealth. Second, differences in saving rates across households are important when accounting for late 19th century distribution of wealth in the U.S., for the increase in wealth inequality suggested by Williamson (1991) and Lindert (2000) as well as for the stability of the wealth distribution after World War II. The model economy that best reproduces the U.S. experience for the period 1870-1970 is the low minimum consumption economy, hereafter referred to as the benchmark economy.

Our results are consistent with three stylized facts of U.S. data, as stated by Huggett and Ventura (2000): (i) The aggregate saving rate is roughly constant over long periods, (ii) household saving rates increase strongly with household income in cross-section data and (iii) income inequality does not increase over long time periods. The third fact mat also apply to wealth inequality since it has been very stable in the post Second World War period. Our results match facts (i) and (iii) since our model economy reaches its balanced growth path very early. Fact (ii) is also reproduced and is driven by the dependence of the household's IES on its level of 
wealth. Fig. 5 shows the saving rates for the aforementioned deciles. The first thing that calls our attention is the enormous difference of saving rates across deciles: households in the 10th decile save 50.35 percent of their income in the steady state, whereas the saving rate of those in the 7 th decile is 13.92 percent. Most of the aggregate investment is comprised of the savings of the top decile: 69.09 percent of the investment in the steady state is due to savings of the wealthiest individuals. These differences in saving rates across wealth deciles are consistent with Avery and Kennickell's (1991) findings. They report that almost all the net saving between 1983 and 1986 was made by the top decile of the distribution.

Notice that income inequality in our model economy is very low compared to that observed in the U.S. data. Dí az-Gimenez et al. (1997) report a Gini coefficient for earnings of 0.63 in 1992. Atkinson (1997) finds a Gini coefficient for income in 1970 of around 0.40 . This model, therefore, underestimates the level of income inequality, largely because we have ignored differences in human capital across households and idiosyncratic uncertainty in earnings. As we mentioned in the Introduction, the main focus of this paper is to understand how differences in initial wealth holdings are propagated through time in a model in which there is no heterogeneity in labor earnings. The objective of this paper is to assess the quantitative significance of this one channel using the U.S. experience within the period 1870-1970 as an illustrative example.

\section{Wealth inequality and TFP growth}

In this paper we have focused on wealth inequality. We have seen that once we introduce a minimum consumption requirement, the standard neoclassical growth model can account for the observed patterns of wealth inequality in the U.S. economy between 1870 and 1970. In this section we want to analyze which forces drive the evolution of the wealth distribution. Intuitively, we can see that the length of the transition path plays a central role. The length of the transition path depends on the level of the IES and on the level of TFP growth. Here we want to explore the relationship between the evolution of inequality and the level of TFP growth.

\subsection{Wealth inequality and the length of the transition path}

In our benchmark calibration we assumed that capital accumulation explains half of the sevenfold growth in per capita output over the period 1870-1970. Here we conduct a sensitivity analysis. We study two different model economies in which the contribution of capital to the observed sevenfold growth in output is 65 percent and 40 percent, respectively. This implies a contribution of TFP of 35 percent and 60 percent, respectively. Both model economies have the same capital-output ratio and investment-output ratio along the balanced growth path as the previous economies as well as the same IES for aggregate consumption. The values for the risk aversion parameter $\sigma$ and the (de-trended) value for the minimum consumption $\alpha$ are those of the low minimum consumption economy already studied. 
A contribution of capital of 65 percent implies a balanced growth rate of output of 1.04 percent and a TFP growth rate equal to 0.68 percent. Recall that in the benchmark economy these figures were 1.48 and 0.97 percent, respectively. Also, the value of initial capital as a fraction of the (de-trended) level of capital stock in the balanced growth path is lower-7.01 percent, while it was 25.86 percent in the benchmark model. Alternatively, a contribution of capital of 40 percent implies a balanced growth rate of output of 1.91 percent and a TFP growth rate equal to 1.25 percent. The value of initial capital as a fraction of the (de-trended) level of capital stock in the balanced growth path is 84.97 percent.

When capital accumulation explains 65 percent of total growth, per capita income reaches 99 percent of its value in the steady state after 51 periods, whereas the same transition requires only 43 periods in the benchmark model. If we assume, instead, that capital accumulation only explains 40 percent of total growth, then the steady state is reached after only 20 periods. Tables 10 and 11 present some statistics that describe the transitional dynamics in these two new model economies. These tables show that the transition path is longer when we assume a larger contribution of capital. Moreover, output growth rate is higher at the beginning and declines more rapidly. Also, the real interest rate starts being higher, 69.08 percent, whereas it is only 10.17 percent when we assume a contribution of 40 percent.

Wealth inequality evolves very differently in the two economies. Fig. 8 shows that the Gini coefficient of wealth displays an inverted U shape, whereas Fig. 9 shows that inequality is strictly decreasing. Tables 12 and 13 show some of the distributional statistics generated by the model. Notice that the results found when we assume a capital contribution of 40 percent are very similar to those of our benchmark low minimum consumption economy. The main difference is that in our benchmark economy there is a (brief) period of increasing wealth inequality, as in the data reported by Lindert (2000) and Williamson (1991).

Table 10

Output growth rates for selected periods

\begin{tabular}{llll}
\hline & $1870-1900$ & $1870-1913$ & $1913-1970$ \\
\hline Model (fraction $=65 \%)$ & 3.90 & 3.13 & 1.07 \\
Model (fraction $=40 \%)$ & 2.08 & 2.04 & 1.92 \\
Maddison $(1987)$ & - & 4.20 & 3.14 \\
\hline
\end{tabular}

Table 11

Aggregate gross saving rate for selected periods (\%)

\begin{tabular}{llr}
\hline & 1870 & 1900 \\
\hline Model (fraction $=65 \%$ ) & 21.13 & 23.05 \\
Model (fraction $=40 \%$ ) & 22.59 & 21.91 \\
Williamson (1991) & 23.00 & 28.00 \\
\hline
\end{tabular}



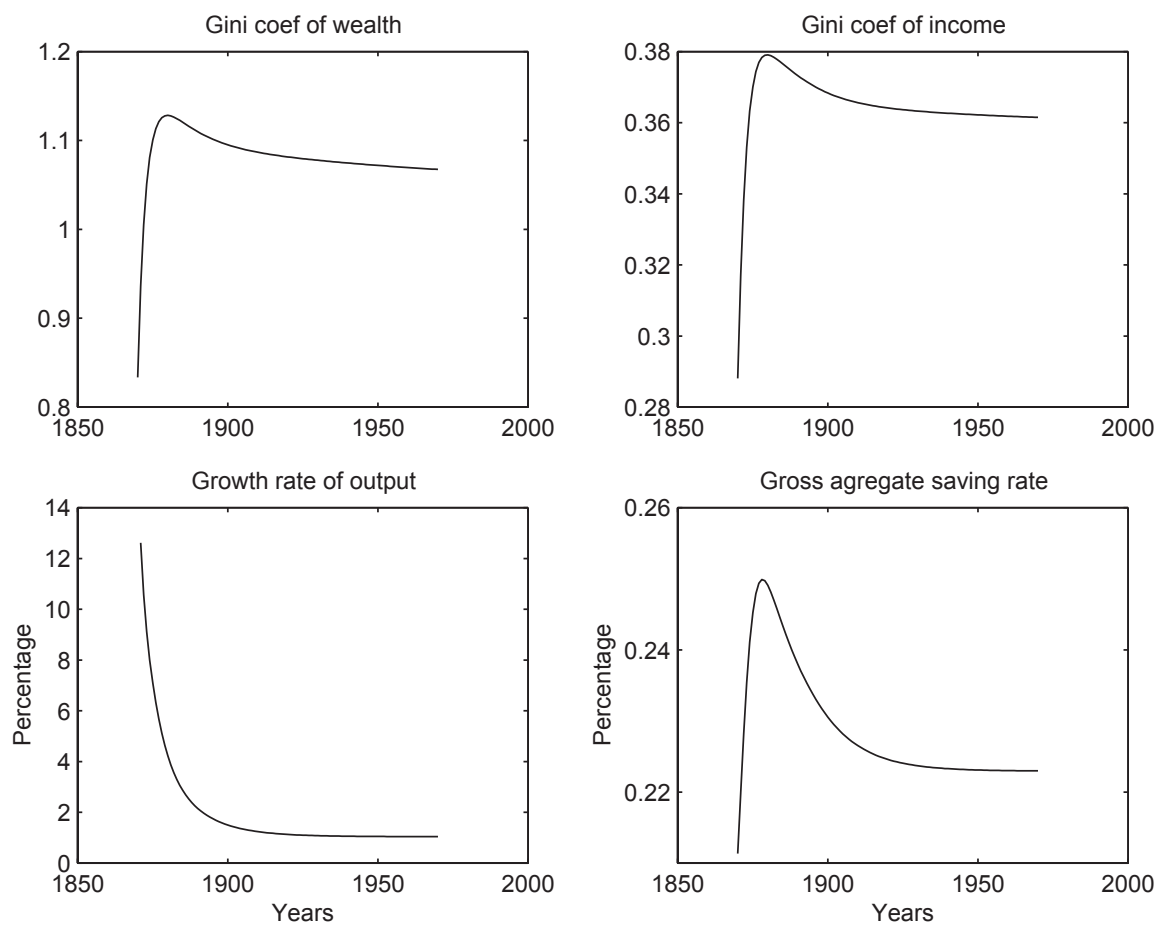

Fig. 8. Evolution of inequality, fraction $=65 \%$.

These two exercises suggest that the length of the transition path is key for the wealth inequality evolution. The length of this transition depends on the contribution of TFP growth and the initial level of capital. For any given level of initial capital, the higher the rate of growth of TFP, the closer the economy is to its steady state and, therefore, the shorter the period of any changes in the wealth distribution. Alternatively, the larger the contribution of capital accumulation to growth, the longer the period of increasing inequality is.

\subsection{The productivity slowdown and the upsurge of inequality}

In the last two decades many developed countries, the U.S. among them, have experienced an upsurge in their levels of income and wealth inequality. This phenomenon has been documented by, among others, Atkinson (1997), Gottschalk and Smeeding (1997), and Wolff (1994). On the other hand, over the period 1970-1990 the U.S. economy experienced a slowdown in the growth rate of TFP, per capita income, capital, and consumption. These observations suggest that the decrease in TFP growth rate may have affected the evolution of the wealth distribution. 

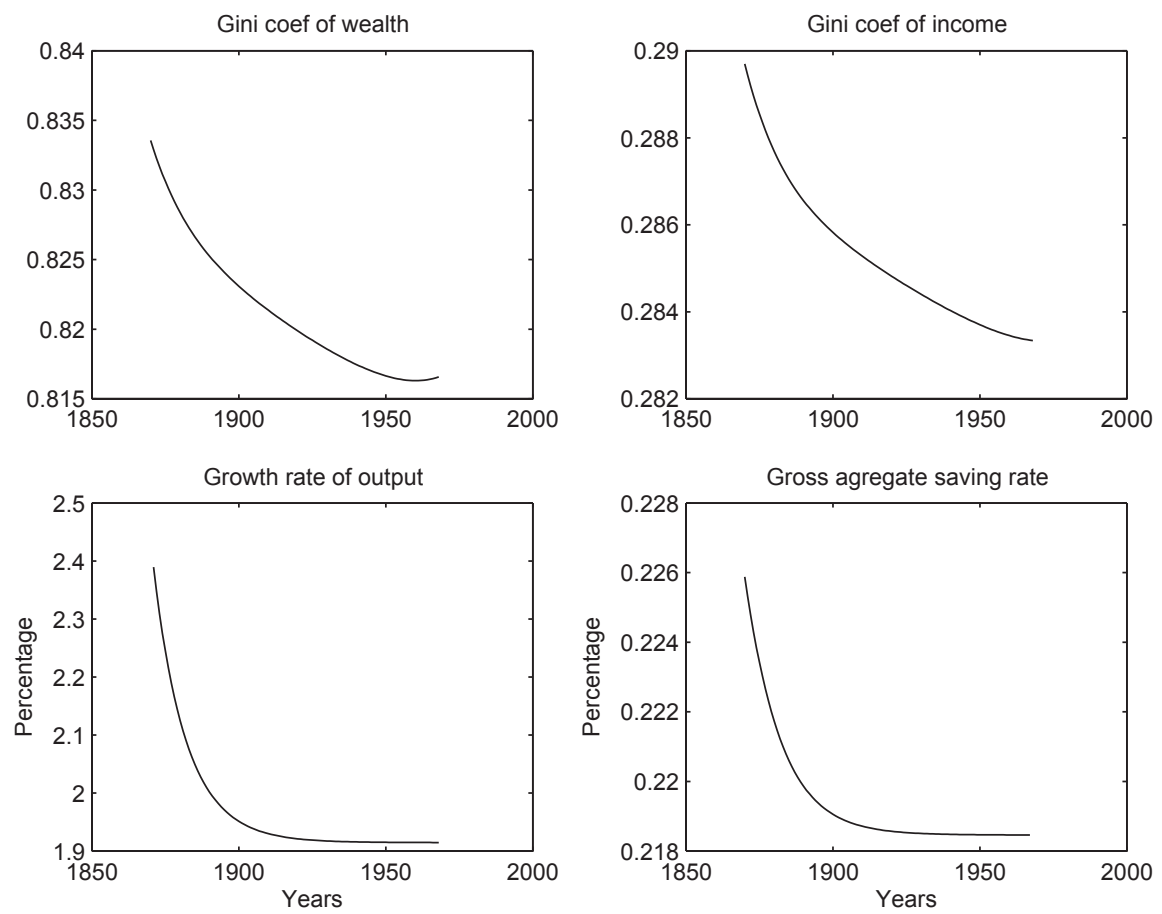

Fig. 9. Evolution of inequality, fraction $=40 \%$.

Table 12

Wealth distribution along the balanced growth path

\begin{tabular}{lrrrrr}
\hline & \multicolumn{2}{l}{ Quintiles (Share \%) } & \\
\cline { 2 - 6 } & \multicolumn{1}{c}{ 1st } & 2nd & 3rd & 4th & 5th \\
\hline Model (fraction $=65 \%$ ) & -4.81 & -3.70 & -0.26 & 11.66 & 97.11 \\
Model (fraction $=40 \%)$ & 1.02 & 1.87 & 4.50 & 13.62 & 78.98 \\
U.S. 1962 & -0.70 & 1.00 & 5.40 & 13.40 & 81.00 \\
\hline
\end{tabular}

Table 13

Wealth distribution along the balanced growth path

\begin{tabular}{llll}
\hline & \multicolumn{2}{l}{ Share $(\%)$} & \\
\cline { 2 - 4 } & Bottom $80 \%$ & 2nd $10 \%$ & Top $10 \%$ \\
\hline Model (fraction $=65 \%)$ & 2.89 & 10.15 & 86.95 \\
Model (fraction $=40 \%$ ) & 21.02 & 11.12 & 68.87 \\
U.S. 1962 & 19.10 & 14.00 & 66.90 \\
\hline
\end{tabular}


Here we want to explore how our model behaves when subjected to a change in the TFP growth rate like the one experienced in the U.S. economy during the period 1970-1990. Several authors have measured these changes in TFP growth. Gordon (2000), for instance, analyzes data on the non-farm, non-housing sector for the period 1870-1996 and finds that TFP for the period 1870-1913 grew at half the rate the period 1913-1970, and even more slowly in the last period 1970-1996. His estimates, however, would be inappropriate in the context of our model, since he uses a different measure of output and a different share of capital in aggregate production. Instead, we have constructed series for annual GDP and capital consistent with our definitions of output and capital. Using data on hours worked from NIPA (Tables 6.9B and 6.9C) it is possible to assess the TFP growth for the period 1950-1990. Our computations reveal an average TFP growth rate in the 1970 s of just 40.76 percent of average TFP growth in the previous period 1950-1969, whereas the average rate for the 1980s is 86.17 percent. The two upper panels of Fig. 10 show the evolution in TFP growth rate and growth in per capita output. Both decline during the 1970s, after which they rebound. The last panel in Fig. 10 shows the evolution of the capital-output ratio for the period 1950-1990. As we can see, this ratio increases during the 1970s and decreases in the following decade. The gross saving rate (investment rate) exhibits the same behavior during that period. ${ }^{8}$

We conduct the following experiment: we assume that our model economy is in its steady state in 1969: output growth is 1.48 percent and TFP growth is 0.97 percent. We then lower the TFP growth rate to 40.76 percent of its previous value during the next 10 periods, i.e. 1970-1980. This is followed by a period where TFP grows at 86.17 percent of its value from the period 1950-1969. All changes in TFP growth are totally unexpected and households view them as permanent.

Fig. 11, shows the evolution of the Gini coefficient for wealth and income, respectively, the gross savings rate and the capital-output ratio. Notice that the evolution of the capital-output ratio in the model resembles that of the ratio in the data. This behavior can be explained as follows: after a reduction in TFP growth the economy moves towards a new balanced growth path in which the capital-output ratio is higher than it was previously. As a result, households increase their savings and the capital-output ratio increases. Since the economy is fairly close to its new steady state, poorer households increase their saving rate in a higher proportion than do wealthier households and inequality decreases along the transition path. From 1980 to 1990 the rise in TFP growth makes the economy move towards a new balanced growth path in which the capital-output ratio is lower than previously. A lower capital-output ratio implies a higher consumption-output ratio for all households, regardless of their level of wealth. Since households want to smooth consumption along the path, poorer households decrease their saving rate in a higher proportion than do wealthier households so that wealth inequality rises. The upper

\footnotetext{
${ }^{8}$ For the sake of clarity the series figured have been HP $(\lambda=100)$ filtered, though TFP growth has been calculated using the original series.
} 

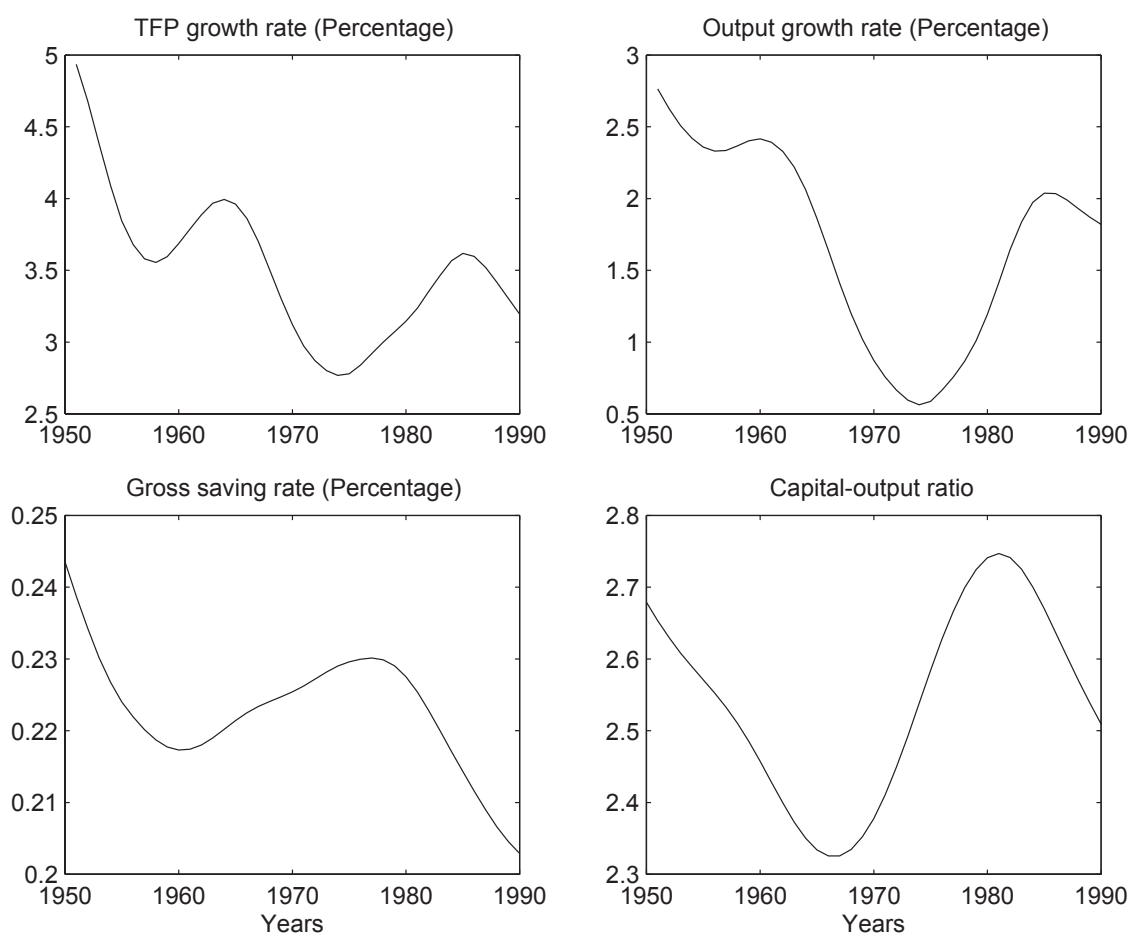

Fig. 10. Data. Evolution of main aggregates.

panel of Fig. 11 shows that inequality decreases during the 1970s but increase afterwards. These results are in line with the data: according to Wolff (1994), wealth inequality increased substantially during the 1980s after a period of intense reduction during the 1970s. Actually, wealth inequality started rising in the mid-1970s, but we should keep in mind that earnings inequality also started rising at that time and that the only source of wealth inequality in our model economy is differences in saving rates across households.

Our experiment predicts a fall in the aggregate savings rate during the 1980s, as has been documented by Avery and Kennickell (1991) and Bosworth et al. (1991), among others. Moreover, the model predicts that the fall in the saving rate is more severe among households in the low wealth deciles than among wealthier households. This is why wealth inequality increases during that period in our model. The evidence we have found about the behavior of the saving rates across deciles for that period is indirect. Bosworth et al. (1991) found that the decline in the saving rate during the 1980s was actually smaller among bonds and stockholders than it was among households with no marketable financial assets. Wolff (1998) reports that more than 43 percent of the wealth of households in the top quintile (richest 20 percent) takes the form of investment assets. 

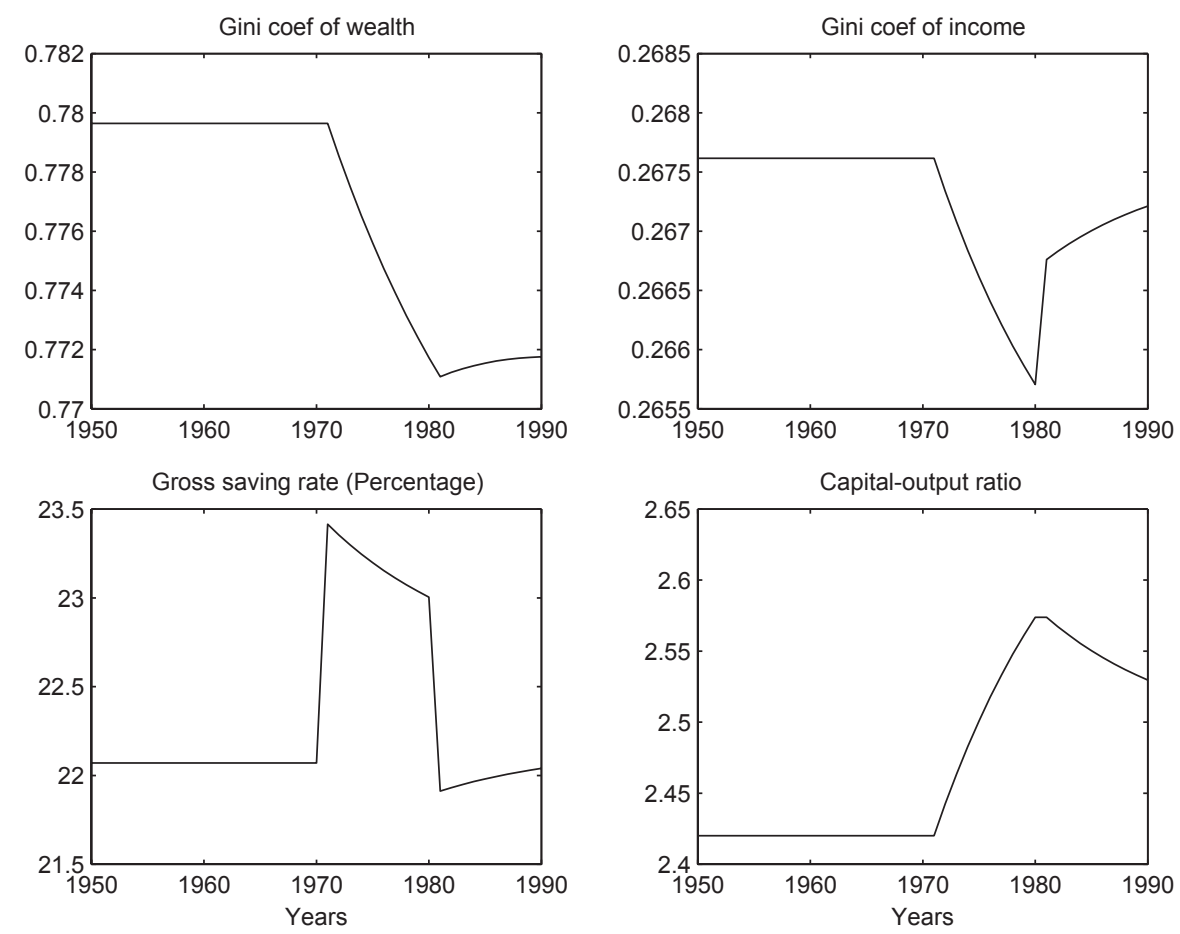

Fig. 11. Model. Evolution of inequality, 1970-1990.

In contrast, almost two thirds of the wealth of the bottom 80 percent of the households was invested in their own home. This evidence supports out model's conclusion that the decline in the saving rate of wealthy households was less severe than that of the poor households. Thus, our experiment suggests that differences in saving rates played an important role in the rise of wealth inequality during the $1980 \mathrm{~s}$ (Figs. 12, and 13).

\section{Final comments}

This paper has shown that differences in saving rates across households are important in accounting for the distributional data in the late 19th century, the increase in wealth inequality suggested by Williamson (1991) and Lindert (2000), and the stability of the wealth distribution after World War II. The only source of inequality in this model is the initial distribution of wealth. Households are identical in their levels of human capital and, thus, there is perfect equality in the earnings distribution. The reason for this strong assumption is to show in a clean way the importance of the capital accumulation channel in understanding the behavior of the 

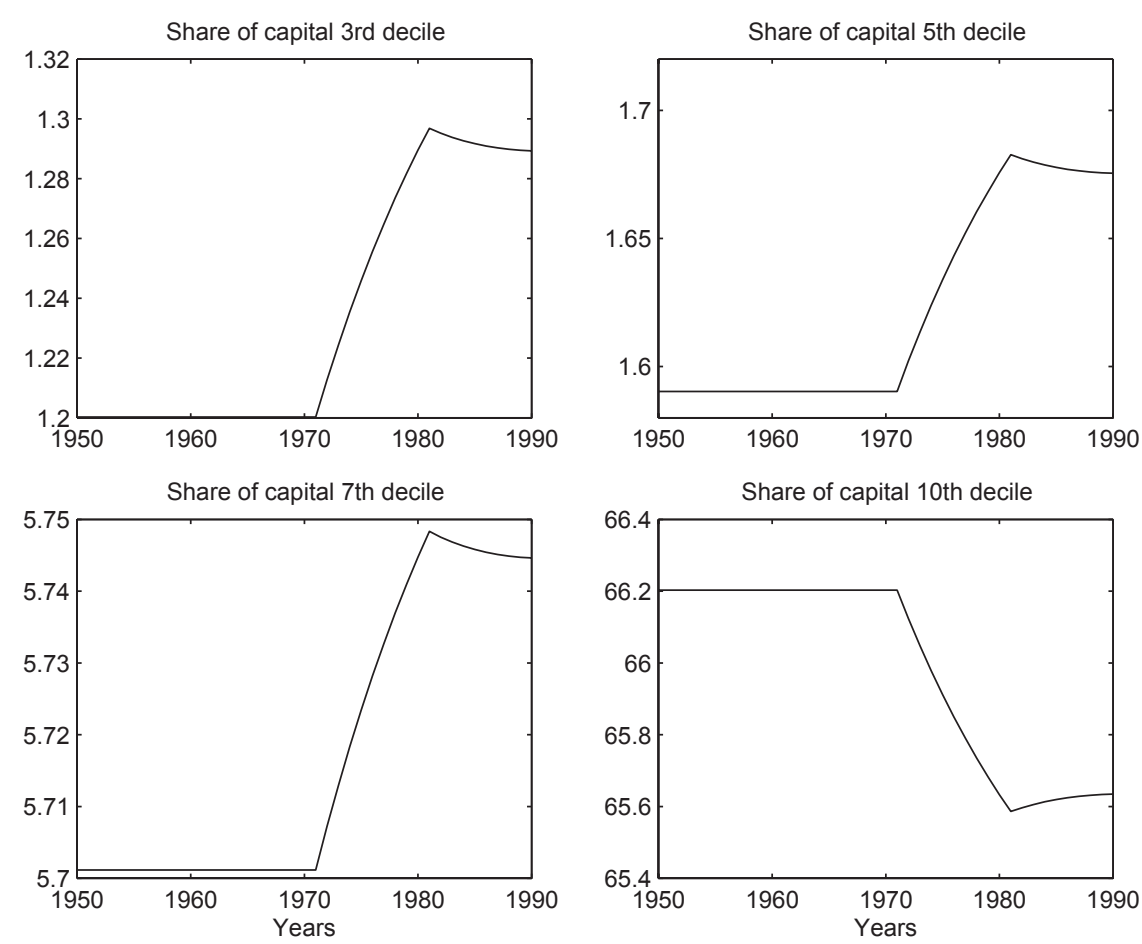

Fig. 12. Model. Shares of capital across deciles, 1970-1990.

wealth distribution for the period studied. We leave the analysis of the interaction between earnings inequality and differences in saving rates across households for further research.

We have made a key assumption: there are perfect capital markets. This assumption allows us to study the transitional dynamics of our model economies in two steps: first we study their aggregate dynamics using the representative agent version of our economies and we focus later on the dynamics of the wealth distribution. This is not to say that capital market imperfections are not important. Rather, we view this paper as a first step in understanding the evolution of the wealth inequality along the 20 th century.

Our experiments suggest that countries that start out a process of sustained growth with the same level of per capita income and the same initial wealth distribution will follow very different paths in wealth inequality depending on their level of TFP growth. We think that this path is worth investigating since the evolution of inequality differs greatly across countries. Finally, this model is also able to account for the upsurge in wealth inequality that followed the slowdown in growth which started in the 1970s in the United States. 

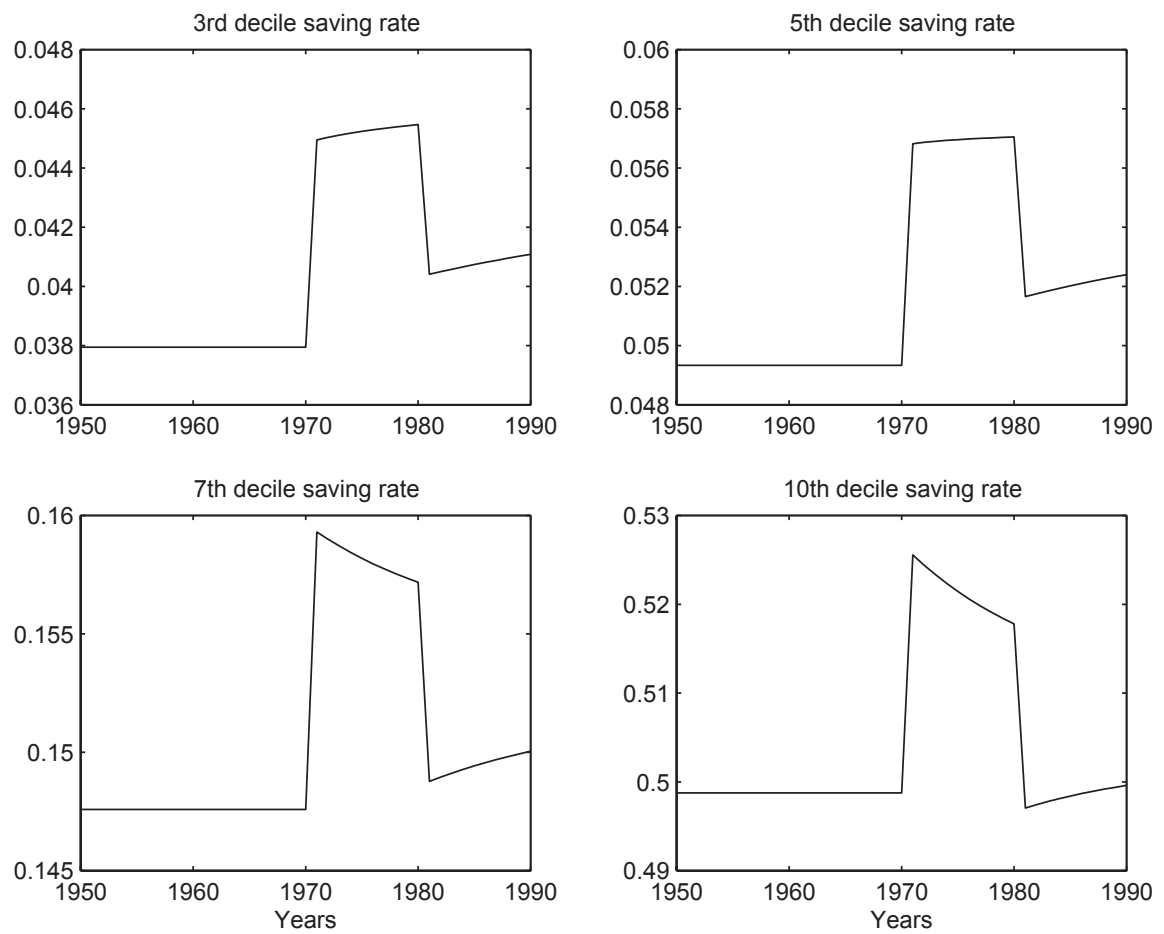

Fig. 13. Model. Saving rate across deciles, 1970-1990.

\section{Appendix}

Proposition 1. The distribution of capital at period $t+1$ is more egalitarian than the distribution of wealth at period $t$ if and only if $B_{t}$ is nonnegative.

Proof. We can write expression (14) as

$$
\sum_{i=1}^{J} \frac{1}{I}\left(1-X_{t+1}^{i}\right) \leqslant \sum_{i=1}^{J} \frac{1}{I}\left(1-X_{t}^{i}\right),
$$

then, substituting (13) in (21) we obtain

$$
\frac{D_{t} k_{t}}{B_{t}+D_{t} k_{t}} \cdot \sum_{i=1}^{J} \frac{1}{I}\left(1-X_{t}^{i}\right) \leqslant \sum_{i=1}^{J} \frac{1}{I}\left(1-X_{t}^{i}\right),
$$

which holds true for $B_{t}$ nonnegative. Recall that $\sum_{i=1}^{J}(1 / I) X_{t}^{i}$ should be less than or equal to $J / I$, which is the fraction of aggregate wealth held by groups 1 to $J$ assuming capital is evenly distributed across agents. 
Lemma 1. Factor $B_{t}$ can be expressed as

$$
B_{t}=\frac{M_{t}\left((1-\theta) y_{t}-\alpha_{t}\right)}{1+n} \sum_{s=t}^{\infty} \frac{p_{s}}{p_{t}} \frac{c_{s}-\alpha_{s}}{c_{t}-\alpha_{t}}\left[1-\frac{\frac{\left(1-x_{t}\right) y_{t}-\alpha_{t}}{(1-\theta) y_{t}-\alpha_{t}}}{\frac{\left(1-x_{s}\right) y_{s}-\alpha_{s}}{(1-\theta) y_{s}-\alpha_{s}}}\right]
$$

for any period $t$.

Proof. Starting from expression (11) and the expression for $M_{t}$ given in (8), we can express factor $B_{t}$ as

$$
B_{t}=\frac{M_{t}}{1+n}\left[\sum_{t=s}^{\infty} \beta^{(s-t) / \sigma}(1+n)^{(s-t) / \sigma}\left(\frac{p_{s}}{p_{t}}\right)^{(\sigma-1) / \sigma}\left(w_{t}-\alpha_{t}\right)-\sum_{t=s}^{\infty}\left(\frac{p_{s}}{p_{t}}\right)\left(w_{s}-\alpha_{s}\right)\right] .
$$

From household $i$ 's problem first order conditions,

$$
c_{s}^{i}-\alpha_{s}=\beta^{(s-t) / \sigma}(1+n)^{(s-t) / \sigma}\left(\frac{p_{s}}{p_{t}}\right)^{-1 / \sigma}\left(c_{t}^{i}-\alpha_{t}\right) \quad \text { for all } t .
$$

Thus, aggregating across households and some algebra, we obtain that

$$
\frac{p_{s}}{p_{t}}=\beta^{s-t}(1+n)^{s-t}\left[\frac{c_{s}-\alpha_{s}}{c_{t}-\alpha_{t}}\right]^{-\sigma},
$$

where $c_{t}$ denotes aggregate consumption in period $t$. We plug this expression into (24) and we obtain

$$
B_{t}=\frac{M_{t}}{1+n} \sum_{t=s}^{\infty}\left[\frac{\left(c_{s}-\alpha_{s}\right)\left(w_{t}-\alpha_{t}\right)-\left(c_{t}-\alpha_{t}\right)\left(w_{s}-\alpha_{s}\right)}{c_{t}-\alpha_{t}}\right] .
$$

We know that the wage $w_{t}$ is the fraction $1-\theta$ of aggregate per capita income $y_{t}$ and calling $x_{t}$ the aggregate savings rate, $c_{t}=\left(1-x_{t}\right) y_{t}$. After some algebra we obtained the desired expression.

Corollary 2. The Gini coefficient at any period t depends on the initial distribution and the evolution of the aggregate variables,

$$
G_{t+1}=\prod_{r=0}^{t}\left(\frac{D_{r} k_{r}}{B_{r}+D_{r} k_{r}}\right) G_{0} .
$$

Proof. It follows from Proposition 1, expression (13), and the definition of the Gini coefficient,

$$
G_{t}=\frac{\sum_{j=1}^{I}\left(\sum_{i=1}^{j}(1 / I)\left(1-X_{t}^{i}\right)\right)}{\sum_{j=1}^{I} \sum_{i=1}^{j} 1 / I} .
$$




\section{References}

Aghion, P., Caroli, E., García-Penalosa, C., 1999. Inequality and economic growth: the prespective of the new growth theories. Journal of Economic Literature 37, 1615-1660.

Atkeson, A., Ogaki, M., 1996. Wealth-varying intertemporal elasticities of substitution: evidence from panel and aggregate data. Journal of Monetary Economics 38, 507-534.

Atkeson, A., Ogaki, M., 1997. Rate of time preference, intertemporal elasticity of substitution, and level of wealth. Review of Economics and Statistics 79, 564-572.

Atkinson, A.B., 1997. Bringing income distribution in from the cold. Economic Journal 107, 297-321.

Avery, R.B., Kennickell, A.B., 1991. Household saving in the U.S. Review of Income and Wealth 37, 409-432.

Benabou, R., 1996. Inequality and growth. In: Bernanke, B.S., Rotemberg, J. (Eds.), NBER Macroeconomics Annual 1996. MIT Press, Cambridge, pp. 11-74.

Bosworth, B., Burtless, G., Sabelhaus, J., 1991. The decline in savings: evidence from household surveys. Brookings Papers on Economic Activity 1, 183-241.

Caselli, F., Ventura, J., 2000. A representative consumer theory of distribution. American Economic Review 90, 909-926.

Chatterjee, S., 1994. Transitional dynamics and the distribution of wealth in a neoclassical growth model. Journal of Public Economics 54, 97-119.

Chatterjee, S., Ravikumar, B., 1999. Minimum consumption requirements: theoretical and quantitative implications for growth and distribution. Macroeconomic Dynamics 3, 482-505.

Cooley, T.F., Prescott, E.C., 1995. Economic growth and business cycles. In: Cooley, T.F. (Ed.), Frontiers of Business Cycle Research. Princeton University Press, Princeton, pp. 1-38 (Chapter 1).

Díaz-Gimenez, J., Quadrini, V., Ríos-Rull, J.V., 1997. Dimensions of inequality: facts on the U.S. distribution of earnings, income and wealth. Federal Reserve Bank of Minneapolis Quarterly Review 21, 3-21.

Gordon, R.J., 2000. Interpreting the "One Big Wave" in U.S. long-term productivity growth. Manuscript, Northwestern University.

Gottschalk, P., Smeeding, T., 1997. Cross-national comparisons of earnings and income inequality. Journal of Economic Literature 35, 633-687.

Huggett, M., Ventura, G., 2000. Understanding why high income households save more than low income households. Journal of Monetary Economics 45, 361-397.

King, R.G., Rebelo, S., 1993. Transitional dynamics and economic growth in the neoclassical model. American Economic Review 83, 908-931.

Kuznets, S., 1955. Economic growth and income inequality. American Economic Review 45, $1-28$.

Lindert, H.L., 2000. Three centuries of inequality in britain and america. In: Atkinson, A.B., Bourguignon, F. (Eds.), Handbook of Income Distribution, vol. 1. Elsevier Science, Amsterdam, pp. 167-216.

Maddison, A., 1982. Monitoring the World Economy: 1820-1992. Paris and Washington, DC, Development Centre Studies, O.C.D.E.

Maddison, A., 1987. Growth and slowdown in advanced capitalist economies: techniques of quantitative assessment. Journal of Economic Literature 25, 649-688.

Obiols-Homs, F., Urrutia, C., 2003. Evolution of the distribution of assets in the neoclassical growth model. Economic Theory, forthcoming.

Ogaki, M., Ostry, J., Reinhart, C.E., 1996. Savings behavior in low and middle income developing countries. A comparison. IMF Staff Papers 43, 38-71.

S.T. Rebelo, 1992. Growth in open economies. Carnegie-Rochester Conference Series on Public Policy, vol. 36, pp. 5-46.

Rosenzweig, M., Wolpin, K.I., 1993. Credit market constraints, consumption smoothing, and the accumulation of durable production assets in low-income countries: investment in bullocks in India. Journal of Political Economy 101, 223-244. 
Stiglitz, J.E., 1969. Distribution of income and wealth among individuals. Econometrica 37, 297-382.

Williamson, J.G., 1991. Inequality, Poverty, and History. Blackwell, Oxford and Cambridge.

Wolff, E.N., 1994. Trends in household wealth in the united states, 1962-1983 and 1983-1989. Review of Income and Wealth 40, 143-174.

Wolff, E.N., 1998. Recent trends in the size distribution of household wealth. Journal of Economic Perspectives 12, 131-150. 